2018-10-31

\title{
Bacterial Metabolism of C1 Sulfur Compounds
}

\author{
Boden, Rich
}

http://hdl.handle.net/10026.1/12734

10.1007/978-3-319-50418-6_9

Springer Nature Switzerland

All content in PEARL is protected by copyright law. Author manuscripts are made available in accordance with publisher policies. Please cite only the published version using the details provided on the item record or document. In the absence of an open licence (e.g. Creative Commons), permissions for further reuse of content should be sought from the publisher or author. 


\title{
Bacterial Metabolism of $\mathbf{C}_{1}$ Sulfur Compounds
}

\author{
Rich Boden and Lee P. Hutt
}

\section{Contents}

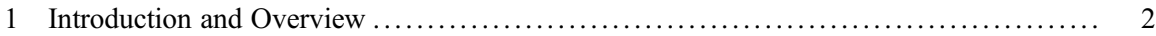

2 Handling, Quantifying, and Synthesizing $C_{1}$ Organosulfur Compounds $\ldots \ldots \ldots \ldots \ldots \ldots$. 5

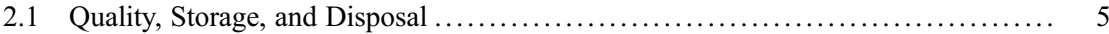

2.2 Determination of $\mathrm{C}_{1}$ Organosulfur Compounds in Cultures .................... 8

2.3 Isotopic Labeling for Ecological and Physiological Studies .................... 12

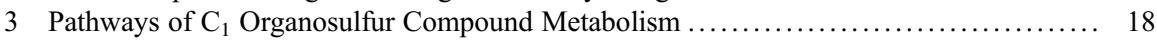

3.1 De Bont Pathway .................................................. 20

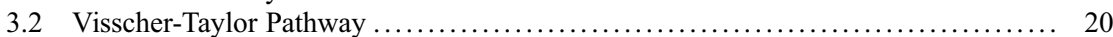

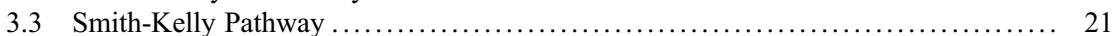

3.4 De Zwart-Kuenen Pathway ........................................... 22

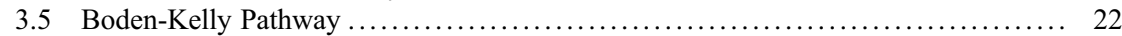

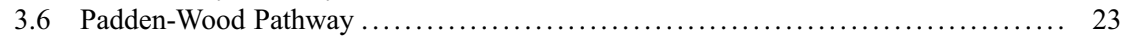

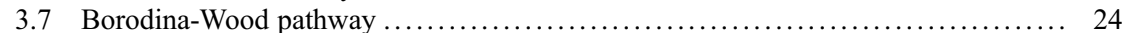

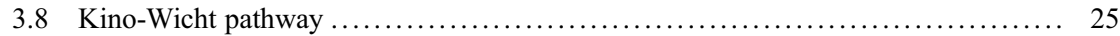

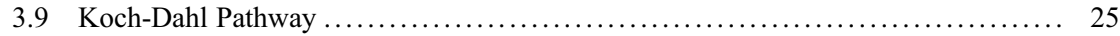

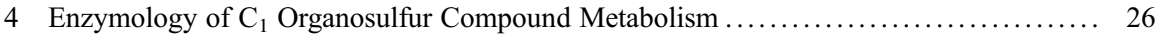

4.1 Dissimilatory Dimethylsulfide Monooxygenase (EC 1.14.13.131) ............ 27

4.2 Assimilatory Dimethylsulfide $S$-Monooxygenase $(E C$ 1.8.1.x) ............... 28

4.3 Dissimilatory Dimethylsulfide Demethylase (EC 2.1.1.x) .................. 29

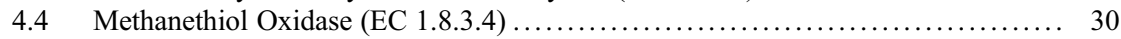

R. Boden $(\bowtie)$

School of Biological and Marine Sciences, Faculty of Science and Engineering,

University of Plymouth, Plymouth, UK

Sustainable Earth Institute, Faculty of Science and Engineering, University of Plymouth, Plymouth, UK

e-mail: rich.boden@plymouth.ac.uk

\section{P. Hutt}

School of Biological and Marine Sciences, Faculty of Science and Engineering,

University of Plymouth, Plymouth, UK

e-mail: lee.hutt@plymouth.ac.uk

F. Rojo (ed.), Aerobic Utilization of Hydrocarbons, Oils and Lipids,

Handbook of Hydrocarbon and Lipid Microbiology,

https://doi.org/10.1007/978-3-319-39782-5_9-1 
4.5 Methanethiol S-methyltransferase (EC 2.1.1.334) ........................ 31

4.6 Dimethylsulfide-Cytochrome $c$ Reductase $(E C$ 1.8.2.4) .................... 31

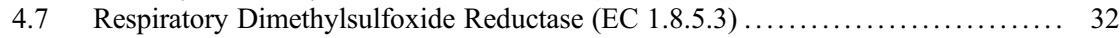

4.8 Dissimilatory Dimethylsulfoxide Reductase (EC $1.8 .1 . x) \ldots \ldots \ldots \ldots \ldots \ldots \ldots, 32$

4.9 Dissimilatory Dimethylsulfone Reductase (EC 1.8.1.17) ................. 33

4.10 Assimilatory Dimethylsulfone Monooxygenase (EC 1.14.14.35), Assimilatory

Methanesulfonate Monooxygenase (EC 1.14.14.34), and Dissimilatory

Methanesulfonate Monooxygenase (EC 1.14.13.111) ................... 33

4.11 Putative Dissimilatory Dimethylsulfide Hydrolase ........................ 35

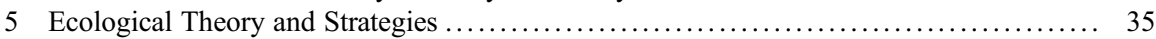

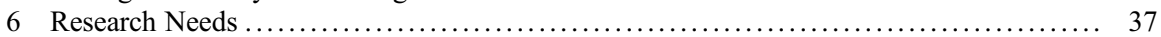

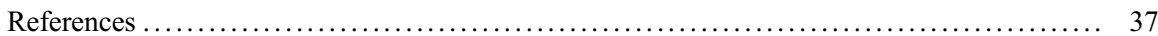

\section{Abstract}

The metabolism of $\mathrm{C}_{1}$ organosulfur compounds by the Bacteria is important in the biogeochemical cycling of sulfur and carbon and in climate regulation in terms of mediating release of, e.g., dimethylsulfide from the oceans. Herein we review the canon of work on the metabolism of dimethylsulfide, dimethylsulfoxide, dimethylsulfone, methanesulfonate, dimethyldisulfide, and methanethiol, in terms of dissimilation to formaldehyde or carbon dioxide when used as carbon and energy sources by methylotrophs or autotrophs, oxidation to sulfite prior to assimilation as sulfur sources, and use as respiratory terminal electron acceptors. We discuss the enzymology of the metabolism of these compounds and propose a revision to the Enzyme Commission classification to some of them where multiple enzymes are clearly grouped under one name at present. We also provide methodologies for enzyme assays, for the safe handling and quantification of these compounds, and for the synthesis of carbon-14, carbon-11, sulfur-34, and sulfur34 compounds for use in physiological and ecological studies.

\section{$1 \quad$ Introduction and Overview}

The diversity of one-carbon $\left(\mathrm{C}_{1}\right)$ compounds containing sulfur is given in Table 1 , including both organic and inorganic examples, and the abbreviations for them used in this chapter. The bacterial metabolism of $\mathrm{C}_{1}$ organosulfur compounds is largely limited in understanding to methanethiol (MT), dimethylsulfide (DMS), dimethylsulfoxide (DMSO), dimethylsulfone $\left(\mathrm{DMSO}_{2}\right)$, methanesulfonate (MSA), and dimethyldisulfide (DMDS), but as Table 1 shows, there is considerable scope for broadening our understanding with many unstudied compounds with regard to microbiology.

The roles, sources, sinks, and chemistry of the $\mathrm{C}_{1}$ organosulfur compounds in the environment (atmospheric chemistry, etc.) are touched on in this chapter where important, but for good reviews on core aspects of the subject, the reader should consult Kelly (1996), Keine (1993, 1996), Wood (1996), and Kelly et al. (1993) for short reviews and perspectives that, while over 20 years old, are very useful - for a longer and more up-to-date review on the subject, Schäfer et al. (2010) give much 
Table 1 Diversity and properties of one-carbon $\left(\mathrm{C}_{1}\right)$ sulfur compounds, defined by their absence of carbon-carbon bonds

\begin{tabular}{|c|c|c|c|}
\hline Compound and abbreviation & Melting point $\left({ }^{\circ} \mathrm{C}\right)$ & Boiling point $\left({ }^{\circ} \mathrm{C}\right)$ & Formula \\
\hline \multicolumn{4}{|l|}{ Organic } \\
\hline Methanethiol (MT) & -123 & +6 & $\mathrm{CH}_{3} \mathrm{SH}$ \\
\hline Methanethial $\left(\mathrm{CH}_{2} \mathrm{~S}\right)^{\mathrm{a}}$ & N.D. & N.D. & $\mathrm{CH}_{2} \mathrm{~S}$ \\
\hline 1,2,3-trithiane (Thioform) & 215 & 230 & $\left(\mathrm{CH}_{2}\right)_{3} \mathrm{~S}_{3}$ \\
\hline Dimethylsulfide (DMS) & -98 & +35 & $\left(\mathrm{CH}_{3}\right)_{2} \mathrm{~S}$ \\
\hline Dimethylsulfoxide (DMSO) & +19 & +189 & $\left(\mathrm{CH}_{3}\right)_{2} \mathrm{SO}$ \\
\hline Dimethylsulfone $\left(\mathrm{DMSO}_{2}\right)$ & +109 & +248 & $\left(\mathrm{CH}_{3}\right)_{2} \mathrm{SO}_{2}$ \\
\hline Dimethylsulfide (DMDS) & -85 & +110 & $\left(\mathrm{CH}_{3}\right)_{2} \mathrm{~S}_{2}$ \\
\hline Dimethyltrisulfide (DMTS) & -68 & +170 & $\left(\mathrm{CH}_{3}\right)_{2} \mathrm{~S}_{3}$ \\
\hline Dimethyltetrasulfide (DMQS) & N.D. & +243 & $\left(\mathrm{CH}_{3}\right)_{2} \mathrm{~S}_{4}$ \\
\hline Dimethylsulfite $\left(\mathrm{DSMO}_{3}\right)$ & N.D. & +126 & $\left(\mathrm{CH}_{3} \mathrm{O}\right)_{2} \mathrm{SO}$ \\
\hline Dimethylsulfate $\left(\mathrm{DMSO}_{4}\right)$ & -32 & +188 & $\left(\mathrm{CH}_{3} \mathrm{O}\right)_{2} \mathrm{SO}_{2}$ \\
\hline Lenthionine & +60 & N.D. & $\left(\mathrm{CH}_{2}\right)_{2} \mathrm{~S}_{5}$ \\
\hline 1,4,2-dithiazole-5-thione & +78 & +280 & CHNSCSS \\
\hline 1,3,4-oxathiazol-2-one & +36 & +226 & CHNSCOO \\
\hline Methanesulfonate (MSA) $^{\mathrm{b}}$ & - & - & $\mathrm{CH}_{3} \mathrm{SO}_{3}{ }^{-}$ \\
\hline 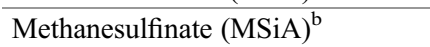 & - & - & $\mathrm{CH}_{3} \mathrm{SO}_{2}^{-}$ \\
\hline Methylmethanesulfonate (MMSA) & +20 & +202 & $\mathrm{CH}_{3} \mathrm{SO}_{3} \mathrm{CH}_{3}$ \\
\hline Thiourea & +182 & & $\mathrm{C}\left(\mathrm{NH}_{2}\right)_{2} \mathrm{~S}$ \\
\hline \multicolumn{4}{|l|}{ Inorganic } \\
\hline Carbon disulfide $\left(\mathrm{CS}_{2}\right)$ & -112 & +46 & $\mathrm{CS}_{2}$ \\
\hline Carbon monosulfide (CS) & N.D. & N.D. & $\mathrm{CS}$ \\
\hline Carbonyl sulfide (COS) & -139 & -50 & COS \\
\hline Thiocarbonate (TC) ${ }^{\mathrm{b}}$ & - & - & $\mathrm{CO}_{2} \mathrm{~S}^{2-}$ \\
\hline
\end{tabular}

${ }^{a}$ Spontaneously oligomerizes into 1,3,5-trithiane

${ }^{b}$ Used in the form of the sodium or potassium salts, which are currently both commercially available for both MSA and MSiA

more depth. Obviously, the reader is directed to Charlson et al. (1987) for the overarching significance of these compounds in the environment, particularly DMS.

In this chapter, we cover the physiological pathways of $\mathrm{C}_{1}$ organosulfur compound metabolism, as well as give detail on each enzyme involved and the structure, function, ecology, and evolution thereof. Since the assay methods for these enzymes have not been curated in any other text, we have included them for completeness. We also give consideration to the practicalities and safety of working with $C_{1}$ organosulfur compounds, as well as methods for their determination in the microbiology laboratory and methods for the synthesis of stable (carbon-13, sulfur-34) and radiolabeled (carbon-11, carbon-14, sulfur-35) compounds for use in physiological and ecological studies - this is particularly important since some of the key questions and gaps in our understanding can (at present) only be resolved using such methodologies and these labeled compounds are not commercially available, or, where they are, it is for $>£ 20,000$ (US\$26,500, €23,000) as a custom synthesis, which 
prohibits work for many laboratories. Since these methods are not especially complex, we have included them with hopefully enough detail for the non-chemist to reproduce them without too much difficulty!

The oxidation of $\mathrm{C}_{1}$ organosulfur compounds to sulfate or partially to other $\mathrm{C}_{1}$ organosulfur species is well known in methylotrophic and heterotrophic Bacteria, respectively. For illustration of the bioenergetics of these oxidations, those of dimethylsulfide (DMS), dimethylsulfoxide (DMSO), dimethylsulfone $\left(\mathrm{DMSO}_{2}\right)$, methanethiol (MT), and dimethyldisulfide (DMDS) to sulfate and carbon dioxide are given, along with the oxidation of DMS to DMSO found in heterotrophs (cf. Boden et al. 2011a), with their Gibbs energy changes $\left(\Delta G^{\circ}\right)$ determined from parameters obtained from Zhdanov (1985), Ross (1985), and Galus (1985), on the basis of $298.15 \mathrm{~K}, 1 \mathrm{bar}$, and all solutes at $1 \mathrm{M}$ concentration. For comparison, consider the energy requirement of ATP and $\mathrm{NAD}(\mathrm{P}) \mathrm{H}$ biosynthesis, viz., $\mathrm{ADP}+\mathrm{HPO}_{4}{ }^{2-} \rightarrow$ ATP $+\mathrm{H}_{2} \mathrm{O}, \Delta G^{\circ}=+46.1 \mathrm{~kJ} / \mathrm{mol}$ ATP produced, and $\mathrm{NAD}^{+}+\mathrm{H}^{+}+e^{-} \rightarrow \mathrm{NADH}, \Delta G^{\circ}=+83.4 \mathrm{~kJ} / \mathrm{mol} \mathrm{NADH}$ produced (that of NADPH is very similar; thus we have not shown it) - Kelly (1978) made used of these values to ascertain "best case scenario" maxima for ATP and NAD(P)H generation from electron donors, e.g., for the first reaction given, the oxidation of DMS to sulfate and carbon dioxide, thus, could at most yield 23 mol ATP or 12 mol NAD(P)H, which can then be related to the energetic requirements of the various carbon assimilation pathways and viability as an electron donor can be examined - as such, Gibbs energy changes can be a very useful tool when comparing electron donors in a biologically meaningful way.

$$
\begin{aligned}
& \left(\mathrm{CH}_{3}\right)_{2} \mathrm{~S}+3 \mathrm{O}_{2}+2 \mathrm{H}_{2} \mathrm{O} \rightarrow 2 \mathrm{CO}_{2}+\mathrm{SO}_{4}{ }^{2-}+10 \mathrm{H}^{+} \\
& \Delta G^{\circ}=-1,068 \mathrm{~kJ} / \mathrm{mol} \text { DMS oxidized } \\
& \left(\mathrm{CH}_{3}\right)_{2} \mathrm{SO}+3 \mathrm{O}_{2}+\mathrm{H}_{2} \mathrm{O} \rightarrow 2 \mathrm{CO}_{2}+\mathrm{SO}_{4}{ }^{2-}+8 \mathrm{H}^{+} \\
& \Delta G^{\circ}=-1,216 \mathrm{~kJ} / \mathrm{mol} \text { DMSO oxidized } \\
& \left(\mathrm{CH}_{3}\right)_{2} \mathrm{SO}_{2}+3 \mathrm{O}_{2} \rightarrow 2 \mathrm{CO}_{2}+\mathrm{SO}_{4}{ }^{2-}+6 \mathrm{H}^{+} \\
& \Delta G^{\circ}=-1,262 \mathrm{~kJ} / \mathrm{mol} \mathrm{DMSO}_{2} \text { oxidized } \\
& \mathrm{CH}_{3} \mathrm{SH}+2 \mathrm{O}_{2}+2 \mathrm{H}_{2} \mathrm{O} \rightarrow \mathrm{CO}_{2}+\mathrm{SO}_{4}{ }^{2-}+8 \mathrm{H}^{+} \\
& \Delta G^{\circ}=-656 \mathrm{~kJ} / \mathrm{mol} \text { MT oxidized } \\
& \left(\mathrm{CH}_{3}\right) \mathrm{S}_{2}+4 \mathrm{O}_{2}+4 \mathrm{H}_{2} \mathrm{O} \rightarrow 2 \mathrm{CO}_{2}+2 \mathrm{SO}_{4}{ }^{2-}+14 \mathrm{H}^{+} \\
& \Delta G^{\circ}=-1,347 \mathrm{~kJ} / \mathrm{mol} \text { DMDS oxidized } \\
& \left(\mathrm{CH}_{3}\right)_{2} \mathrm{~S}+1 / 2 \mathrm{O}_{2} \rightarrow\left(\mathrm{CH}_{3}\right)_{2} \mathrm{SO} \\
& \Delta G^{\circ}=-89 \mathrm{~kJ} / \mathrm{mol} \text { DMS oxidized }
\end{aligned}
$$




\section{Handling, Quantifying, and Synthesizing $C_{1}$ Organosulfur Compounds}

\subsection{Quality, Storage, and Disposal}

While $\mathrm{DSMO}_{2}$ is a stable, easy to store and handle compound, DMSO and DMS pose some complexities. Both are commonly contaminated even when "99.9999\%" analytical grade - the moment they are opened, they start to oxidize, unless kept under argon. We detail procurement options in the following sections, but DMS and DMSO should be stored at room temperature in non-actinic glass. Neat DMS is best stored in the fume hood itself as even closed bottles sealed in paint cans of vermiculite still smell. Neat DMSO should be stored in a desiccator over silica gel in vacuo, and the bottle of DMSO should contain $4 \AA$ molecular sieve - it is often shipped with it in place, but adding more from time to time is best. $\mathrm{DSMO}_{2}$ does not require any special storage and solutions are very stable.

For disposal of DMS and glassware contaminated with it, oxidation to $\mathrm{DMSO}_{2}$ with hypochlorite is used, and Menger and Elrington (1990) report an excellent microemulsion ("the Menger microemulsion") that accomplishes this oxidation very rapidly, with a reduction in smell, which we highly recommend. DSMO and $\mathrm{DSMO}_{2}$ do not require any special disposal.

\subsubsection{Preparation and Use of Dimethylsulfide Solutions in Culture Work}

For all culture work and storage of stock solutions of DMS, gray rubber or butyl rubber septa (vaccine stoppers) should ideally be used. Most work is conducted in septa-sealed containers, and the approximate equivalencies are that we use $30 \mathrm{~mL}$ serum bottles where one would normally use Universal bottles and $250 \mathrm{~mL}$ or $2,000 \mathrm{~mL}$ "QuickFit" Erlenmeyer flasks with a ground-glass socket where a normal Erlenmeyer would normally be used. The latter are sealed using Suba-Seal vaccine stoppers - Sigma-Aldrich sells a range of sizes and colors, and we have found the white ones more resistant to DMS than the traditional red. Suba-Seals are prepared by standing upside-down on a sheet of foil and spraying with three to four coats of Teflon Dry Lubricant Spray (from an electronics supplier) and drying thoroughly before stacking into glass measuring cylinders (they fit inside of one another neatly) and sealing with foil before autoclaving. Alternatively, they can be wrapped individually, with the "inside" end of the packet sealed with a twist and the "outside" end folded closed - this enables the "outside" end to be identified and opened very easily (Dr Ann P. Wood, personal communication). The same coating is applied to serum bottle septa which are autoclaved in beakers. The coating should be replenished after every use. Spent vaccine stoppers are soaked in 1:10 solutions of domestic hypochlorite bleach for $24 \mathrm{~h}$ to remove any DMS and are then washed, dried, coated, and re-autoclaved. For culture work done in serum bottles and QuickFit flasks, gas samples for analysis can easily be removed from the headspace with an appropriate syringe - it is important to use only the 19 gauge $(1.1 \mathrm{~mm}$ outside diameter) needles (orange colored) and "Luer-Lok" syringes, firstly to avoid "coring" the septum and 
secondly to avoid pungent solutions leaking out. For gas samples, a tap or "switch" should be between the needle and syringe. Where no gas sampling is needed, we use ground-glass QuickFit stoppers, clipped or wired into place, which are very useful if just bulking up cells.

For agar plates, small pieces $\left(1^{\prime \prime}\right.$ by $\left.1^{\prime \prime}\right)$ of filter paper (or the discarded "pads" used in between nitrocellulose filters during storage) should be autoclaved in glass Petri dishes. Basal medium is made and poured with no carbon source $(\mathrm{a} \mathrm{pH}$ indicator such as $1 \mathrm{~mL}$ saturated aqueous bromocresol purple per liter is useful in solid media - yellow coloration of the medium indicates full oxidation to sulfate; deeper purple is tetrathionate formation). Once plates have set and been inoculated, a piece of sterile paper is added to the inside of the lid and then in the fume hood, and $5 \mu \mathrm{L}$ DMS is added to the paper. Plates are then stacked in a gas jar, along with an open "DMS bomb" comprising a Bijou tube stuffed with tissue to which $100 \mu \mathrm{L}$ DMS has been added. The jar is then sealed and growth will be observed usually within a week. Owing to long incubation times, some workers add glass Petri dishes containing silica gel to minimize condensation; however, we have found silica gel is often laden with fungal spores and so we do not use it.

For liquid cultures where precision is needed or for analytical work, our protocol is to buy DMS in small bottles from Acros Organics $(10-20 \mathrm{~mL})$ and, once opened, dispose of them after a few weeks as DMSO, $\mathrm{CS}_{2}$, etc. will start to form. We assume neat DMS is sterile and add $73 \mu \mathrm{L}$ to $120 \mathrm{~mL}$ glass serum bottles containing $100.00 \mathrm{~mL}$ glass-distilled, sterile water (from a volumetric glass pipette). We then gently fill the headspace with argon from a $20 \mathrm{~mL}$ syringe to push out the majority of air and seal with crimp seal with a gray rubber septum (see note above re: septa preparation). After shaking for $24 \mathrm{~h}$, this yields a $10.00 \mathrm{mM}$ stock, which is stable at room temperature in the dark for 2-3 weeks. For most culture work, we add this to 2-4 mM final concentration - other work has been successful at c. $50 \mu \mathrm{M}$ concentrations with many repeated additions (Schäfer 2007), but we find this inconvenient as most organisms in our hands tolerate at least $2 \mathrm{mM}$. For the chemostat, $15 \mathrm{mM}$ DMS in the medium feed is easily prepared by sterilizing a glass Universal and lid in a glass beaker and in the fume hood, adding $22.0 \mathrm{~mL}$ DMS into the tube and adding the lid with sterile tongs. It is then taken to the reactor where $20 \mathrm{~L}$ of medium have been prepared in a glass carboy with a hard-rubber stopper or, better still, with a QuickFit "udder" flanged lid to minimize rubber components, which can leak DMS over time. The lid of the Universal is unscrewed as aseptically as possible, the lid of the carboy quickly opened, and the Universal "depth charged" by dropping it in. By the time it hits the bottom and the lid comes off, the lid of the carboy will have been tightly sealed again - this takes practice but it is not difficult to master. After equilibrating overnight with stirring, this will yield a $15 \mathrm{mM}$ solution - there may be an "oil slick" of DMS visible on the surface - this will dissolve and come back out of solution in response to temperature and pressure like the FitzRoy storm glass (Bolton and Ray 1992), but since concentration of substrate in the medium feed should be monitored anyway, it will not pose any issues. While high concentrations in the medium feed can be made up to about $100 \mathrm{mM}$ before saturation is reached, the smell can be unbearable if the chemostat malfunctions, so we do not recommend 
this! All O-rings and tubing on the chemostat should be Viton ${ }^{\circledR}$ and, at the pumps, Viton ${ }^{\circledR}$ Flex. The effluent gas should be passed through a Drechsel bottle of a 1:1 solution of domestic bleach containing a few drops of Antifoam 289 or Antifoam 204 (Sigma-Aldrich) - or better still, the Menger microemulsion - and the treated gas then passed out of a window or into the fume hood. A charcoal filter such as the Carbon Cap 150 (Whatman), which also contains a HEPA filter, is also a prudent addition after the scrubbing bottle, but when used with DMS in the off-gas, reconditioning them should be done in an oven in the fume hood or with a vacuum oven, as the smell will be very strong.

\subsubsection{Preparation and Use of Dimethylsulfoxide Solutions in Culture Work}

Anhydrous analytical-grade DMSO is usually shipped in a bottle with a septum containing molecular sieve ( $4 \AA$ ) to keep it dry, which helps to keep it pure - if the DMSO smells of DMS or like oysters, sweetcorn, etc., it should be disposed of, unless the user can be bothered to purify it by refluxing for $4 \mathrm{~h}$ over calcium oxide under reduced pressure, drying over calcium hydride, and fractionally distilling at reduced pressure under argon - we just buy another bottle! DMSO can be autoclaved but this tends to break down some of it, so we add it after autoclaving, usually neat as it is sterile as sold - a $50 \mathrm{~mL}$ culture requires $71 \mu \mathrm{L}$ DMSO to give a $20 \mathrm{mM}$ solution. For growth on agar plates, it can be added after autoclaving, but the plates become quite hygroscopic and look and feel "damp," causing one's loop to slide around they should thus be stored in a sealed box. Rather than drying the air and risking cracking the plates, we just flush the box with dry nitrogen or argon to omit water vapor as much as possible.

\subsubsection{Preparation and Use of Dimethylsulfone Solutions in Culture Work}

$\mathrm{DMSO}_{2}$ solutions are autoclavable and very stable, and no special handling is needed - cultures can be grown in flasks with foam bungs, and $\mathrm{DMSO}_{2}$ can be added to solid media in the normal way before autoclaving. We usually use $20 \mathrm{mM}$ in liquid cultures but $10 \mathrm{mM}$ is more than enough in agar plates. For the chemostat, we have used 0.1 $\mathrm{M} \mathrm{DMSO}_{2}$ for freshwater/soil organisms (Boden et al. 2011b), but in $\mathrm{NaCl}$-containing media, the $0.1 \mathrm{M} \mathrm{H}_{2} \mathrm{SO}_{4}$ produced during growth, and thus the $0.2 \mathrm{~mol} \mathrm{NaOH}$ added per liter by the reactor to neutralize it, results in a heavy precipitation of large crystals of $\mathrm{NaCl}$ and $\mathrm{Na}_{2} \mathrm{SO}_{4}$ into the medium; thus for marine work, lower concentrations are clearly necessary.

DMDS is very similar to DMS which is covered in Sect. 2.2.1 in terms of disposal, handling, and storage. MT being a gas and 10 times more toxic than hydrogen cyanide $\left(L D_{50}\right.$ rat, $2 \mathrm{~h}, 3.3 \mathrm{ppm}$ vs. $36 \mathrm{ppm}$ for $\left.\mathrm{HCN}\right)$ presents a much bigger handling issue. Thankfully the odor threshold of MT is 1 ppb versus $5,000 \mathrm{ppb}$ for $\mathrm{HCN}$, and it is very disagreeable; thus the user is far more likely to leave the area in the event of a leak before a toxic concentration can be reached. 


\subsubsection{Preparation and Use of Methanethiol Solutions in Culture Work}

MT dimerizes in the presence of oxygen to form DMDS over time, and so stock solutions must be carefully prepared. In brief, sterile glass-distilled water is deaerated by bubbling with argon for $30 \mathrm{~min}$ and is then bubbled with gaseous MT in a serum bottle sealed with a butyl rubber crimp seal using two needles. The off-gas is passed through a Drechsel bottle of domestic bleach, which converts most of the waste gas to MSA, preventing risk - this should be done in a ducted fume hood, and it should be ensured that no one is working on the roof as even the diluted gas is toxic and very pungent. In some jurisdictions, it is important to notify the local authorities and gas companies before carrying this out, since the highly diluted smell of MT carried downwind from a fume hood can lead to fear of a natural gas leak some distance from the source. Once done, the solution is stored under a slight overpressure of argon, at $4{ }^{\circ} \mathrm{C}$, and will be around $0.3 \mathrm{M}$ but should be quantified before use, of course. For the chemostat it is in theory possible to use the gas directly, diluted in air, but the off-gas would be so pungent and potentially deadly in the event of the organism dying that we do not condone this! For cultures, MT is usually added to $1-5 \mathrm{mM}$, and for the chemostat, concentrations of $10-20 \mathrm{mM}$ are usual, but considering the smell if the organism dies, keeping the concentration in the chemostat low is prudent - the same tubing, carboys, and so on as DMS should be used.

\subsubsection{Preparation and Use of Methanesulfonate Solutions in Culture Work}

At one time, sodium methanesulfonate was hard to obtain, and thus methanesulfonic acid was titrated against $\mathrm{NaOH}$ and the sodium salt produced, but now it is readily obtained, as are other alkanesulfonates. It is water soluble, stable to autoclaving, and handled much like $\mathrm{DMSO}_{2}$. In cultures, concentrations of $10-20 \mathrm{mM}$ would usually be used, and in the chemostat, $0.1 \mathrm{M}$ is possible, but higher concentrations are not used for the same reason given for $\mathrm{DMSO}_{2}$.

\subsection{Determination of $\mathrm{C}_{1}$ Organosulfur Compounds in Cultures}

In the well-equipped and well-funded laboratory with access to gas chromatography (GC) and high-performance liquid chromatography (HPLC), many of these compounds are easy to determine, and the process can even be automated; however, not all laboratories have access to such equipment, and so we have given colorimetric and other methods here also.

\subsubsection{Dimethylsulfide}

DMS is not difficult to quantify although GC is often thought to be the only way to do it; there are others which we summarize herein, since there are many laboratories worldwide that do not have such instrumentation or wish to use it during fieldwork. 


\section{Gas Chromatography of Culture Headspaces}

For laboratories with access to a GC with a suitable detector, this is a very good option and can be automated. A $1 \mathrm{~m}$ column of $4 \mathrm{~mm}$ caliber packed with Porapak ${ }^{\mathrm{TM}}$ Q (80/100 MT, Phase Separations Ltd) held at $200{ }^{\circ} \mathrm{C}$ with oxygen-free nitrogen at $30 \mathrm{~mL} / \mathrm{min}$ as the carrier gas can be used with a flame ionization detector (FID), with both it and the injector held at $250{ }^{\circ} \mathrm{C}$. One of us has used this (Boden et al. $2010,2011 \mathrm{a}, \mathrm{b})$ method injecting $100 \mu \mathrm{L}$ volumes of headspace gas and using a calibration curve to determine the DMS concentration in the headspace. Relative to $n$-hexane, DMS has a retention time of 0.53 , where $n$-hexane is typically eluted around $4 \mathrm{~min}$ in our hands.

\section{lodometric Determination of Culture Extracts}

$0.2-0.5 \mathrm{~mL}$ volume of culture is extracted using $5 \mathrm{~mL}$ iso-octane $(2,2,4-$ trimethylpentane) in tightly sealed tubes $(10 \mathrm{~mL}$ serum bottles work very well) by shaking for 5-10 min at room temperature. After allowing the phases to separate, $2 \mathrm{~mL}$ of the iso-octane fraction is removed and reacted with $2 \mathrm{~mL} 0.2 \%(w / v)$ elementary iodine in iso-octane, and the absorbance at $300 \mathrm{~nm}$ determined using an optical quartz cuvette. This method works well in the 0-6 mM range (Smith 1988; Kanagawa and Kelly 1986) - we have used it in our laboratory and find it a very suitable alternative to gas chromatography for those who do not have access to the equipment or who require more rapid determination as a large number of samples can be analyzed in quite a short period of time.

\subsubsection{Dimethylsulfoxide}

Quantitation of DMSO is reliant on reduction to DMS, which can be quantified using any of the methods in Sect. 2.1.2 - thus in the following sections, we only cover the reduction steps.

\section{Reduction to DMS Using Stannous Chloride}

$$
\mathrm{DMSO}+\mathrm{SnCl}_{2}+2 \mathrm{HCl} \rightarrow \mathrm{DMS}+\mathrm{SnCl}_{4}+\mathrm{H}_{2} \mathrm{O}
$$

$0.1 \mathrm{~mL}$ culture is placed in a $10 \mathrm{~mL}$ serum bottle, and $0.9 \mathrm{~mL} 0.1 \mathrm{M}$ stannous chloride in concentrated (viz., $37 \%(v / v)$ and not $32 \% \mathrm{v}(v / v)) \mathrm{HCl}$ is added and a vaccine stopper rapidly added and crimped into place. Bottles are incubated at $90{ }^{\circ} \mathrm{C}$ for $2 \mathrm{~h}$ and are then allowed to fully equilibrate to room temperature before determination of DMS. DMSO is determined based on calibration curves made using 0.8-8.0 mM DMSO. There is no interference from $\mathrm{DMSO}_{2}$, but if samples contain DMS, it should be determined in one aliquot and another used for this assay and the former subtracted from the latter to give DMSO (Anness 1981).

\section{Reduction to DMS Enzymatically}

Effectively the same reaction can be done as above but using the enzyme dimethylsulfoxide reductase (EC 1.8.5.3). A recombinant enzyme kit was available from Glycomar Ltd. (UK), but at the time of writing, this does not seem to be on sale. 
The procedure has been outlined previously in full by Hatton et al. (1994), using the enzyme from Rhodobacter capsulatus.

\subsubsection{Dimethylsulfone}

\section{Reduction to MT Using Zinc Amalgam and Vanadium}

Meites and Meites (1948) described a strong reducing agent comprising zinc amalgam and vanadyl sulfate that could reduce oxygen to water, and we have found this suitable for $\mathrm{DMSO}_{2}$ determination in cultures by reduction to methanethiol, which can be determined as outlined elsewhere in this chapter. To $100 \mathrm{~mL} 0.55 \mathrm{M}$ mercuric chloride solution, $100 \mathrm{~g}$ fine zinc powder is added and mixed vigorously for $2 \mathrm{~h}$ at room temperature. The zinc amalgam formed is recovered by filtration at the pump and is washed with about a liter of water before suspending in $100 \mathrm{~mL} 0.1 \mathrm{M}$ vanadyl sulfate solution with rapid stirring. Just before use, concentrated $\mathrm{H}_{2} \mathrm{SO}_{4}$ is added with rapid stirring until bubbles of hydrogen are evident on the surface of the amalgam. About $5 \mathrm{~mL}$ of this reagent is added to $30 \mathrm{~mL}$ serum bottles with $1 \mathrm{~mL}$ of the culture supernate. It is sealed with a butyl rubber bung and crimped and incubated at $70{ }^{\circ} \mathrm{C}$ for $2 \mathrm{~h}$. After equilibration to room temperature, headspace methanethiol was determined and $\mathrm{DMSO}_{2}$ calculated from calibration curves made using 1-50 $\mathrm{mM} \mathrm{DMSO}_{2}$ standards. If DMSO and DMS are present, they will also be reduced and so should be determined separately and subtracted.

\section{Gas Chromatography of Culture Supernates}

Methods for $\mathrm{DMSO}_{2}$ determination at concentrations found in the laboratory have been reported, and these could be (semi)automated to reduce workload burden versus the other methods outlined above, all of which require GC-FID determination of DMS or MT, whereas the methods in this section are "one stop."

A GC with mass spectrometer (GC-MS) can be used with a DB-WAX $30 \mathrm{~m}$ capillary column of $0.25 \mathrm{~mm}$ caliber and $500 \mathrm{~nm}$ film thickness (J\&W Scientific). The column is held at $40{ }^{\circ} \mathrm{C}$ for $1 \mathrm{~min}$ and then rises to $230{ }^{\circ} \mathrm{C}$ at $10^{\circ} \mathrm{C} / \mathrm{min}$. Helium is used as the carrier gas at $1 \mathrm{~mL} / \mathrm{min}$ with the injector and transport line at $250^{\circ} \mathrm{C}$ and $230{ }^{\circ} \mathrm{C}$, respectively. The MS is used in electron impact mode at $70 \mathrm{eV}$ with the ion source at $230{ }^{\circ} \mathrm{C}$ and quadrupole analyzer at $150{ }^{\circ} \mathrm{C} .1 \mu \mathrm{L}$ samples are injected (samples (diluted if need be) are prepared by removing biomass by centrifugation and reacting $2 \mathrm{~mL}$ supernate with $0.2 \mathrm{~mL} 17.5 \%(v / v) \mathrm{HCl}$ and $20 \mathrm{~mL}$ 2,2-dimethoxypropane containing $1.19 \mu \mathrm{g} / \mathrm{mL}\left[\mathrm{D}_{\mathrm{U}}\right]-\mathrm{DMSO}$ as the internal standard; after $30 \mathrm{~s}$, it is vortexed and incubated for $10 \mathrm{~min} ; 27 \mathrm{~g} \mathrm{Na}_{2} \mathrm{CO}_{3}$ is added and after 10 min centrifuged at $13,000 \mathrm{~g}$ for $10 \mathrm{~min}$ ), and $\mathrm{DMSO}_{2}$ is detected and quantified by selected ion monitoring at $79 \mathrm{~m} / \mathrm{z}$. Solutions of $5-500 \mu \mathrm{M} \mathrm{DMSO}_{2}$ can be determined in this way (Takeuchi et al. 2009).

An alternative method uses a $3 \mathrm{~m}$ deactivated glass column of $2 \mathrm{~mm}$ caliber packed with 3\% SP1500 stationary phase on Carbopack B (80/120 MT, Supelco). Helium is used as the carrier gas at $18 \mathrm{~mL} / \mathrm{min}$ and an electrolytic conductivity detector is used. The column is held at $165^{\circ} \mathrm{C}$, the injector at $220^{\circ} \mathrm{C}$, and detector at $175{ }^{\circ} \mathrm{C} .1 \mu \mathrm{L}$ samples are injected, and solutions containing concentrations of 
0.1-23 $\mathrm{mM}$ can be determined in this way (a peak for DMSO appears before $\mathrm{DMSO}_{2}$ ), so they can be determined in mixtures in this way (Lang and Brown 1991). Further GC-FID methods have been reported (Park and Lee 2015; Šatínský et al. 2014) as well as GC-FPD (flame photometric detector, Ogata et al. 1979) methods, all of which could be applied to $\mathrm{DMSO}_{2}$ determination in cultures.

\subsubsection{Methanethiol}

MT can be determined from headspaces with the GC method given for DMS, with a relative to $n$-hexane retention of about 0.3 .

\section{Spectrophotometric Determination}

Culture $(5.00-20.00 \mathrm{~mL})$ is added to a $25 \mathrm{~mL}$ volumetric flask with water to a total volume of $22.0 \mathrm{~mL}$. A reagent solution is prepared by mixing 3 volumes of $0.5 \% \mathrm{~N}$, $N$-dimethyl-p-phenylenediamine hydrochloride in concentrated hydrochloric acid with 1 volume of an iron-nitrate reagent. This is prepared by dissolving $33.8 \mathrm{~g}$ ferric chloride hexahydrate in $250 \mathrm{~mL}$ glass-distilled water and then adding $250 \mathrm{~mL}$ nitric acid, prepared by dissolving $36 \mathrm{~mL}$ boiled concentrated nitric acid in water and diluting to volume. $2.0 \mathrm{~mL}$ of this reagent solution are added to each flask, which is then mixed well and allowed to incubate for $30 \mathrm{~min}$ at $20{ }^{\circ} \mathrm{C}$, before measuring absorbance at $500 \mathrm{~nm}$ against a reagent blank (adapted by the authors from the method of Lodge (1988) for measuring thiols in air).

\subsubsection{Dimethyldisulfide}

DMDS can be determined using GC using the methods given for DMS but has a relative to $n$-hexane retention of about 2.2, which is very long and gives a somewhat splayed peak that takes time to elute - spectrophotometric assay can be more convenient.

\section{Spectrophotometric Determination}

To $1 \mathrm{~mL}$ culture, $2 \mathrm{~mL} n$-hexane is added in a $10 \mathrm{~mL}$ serum bottle and a vaccine stopper added. After shaking for $10 \mathrm{~min}$ at room temperature, the phases are allowed to separate, and the upper phase is removed into an optical quartz $1 \mathrm{~cm}$ pathlength cuvette and the absorbance at $260 \mathrm{~nm}$ determined versus an $n$-hexane blank.

\subsubsection{Methanesulfonate}

Many complex methods have been developed for the detection of MSA in seawater at low ppm levels (e.g., Kolatis et al. 1989), which can no doubt be adapted for use in culture work. Otherwise ion chromatography in a carbonate-bicarbonate buffer or $\mathrm{NaOH}$-acetonitrile, with a suppressed conductivity detector, is the best option (Jagota et al. 1995), as simple colorimetric assays are not possible. 


\subsection{Isotopic Labeling for Ecological and Physiological Studies}

Radiolabeled or stable-isotope-labeled compounds are useful as tracers in physiological or respirometric work or for stable-isotope-labeled metabolomics or stableisotope probing (SIP) in molecular ecology. High chemical purity and defined isotopic purity are obviously important, as is ease of preparation. It is important to note that all procedures must be undertaken in a ducted fume hood and that it is prudent to undertake "dry runs" using non-labeled reagents until confident. For radiolabeling, work must be done in accordance with local regulations, and at many institutions now there is a paucity of fume hoods licensed for radioisotope work, and this should be checked, obviously. Disposal using oxidation methods outlined in Sect. 2.1.2 should be observed, and then any radioisotope waste (which would contain $\left[{ }^{14} \mathrm{C}_{\mathrm{U}}\right]$ - or $\left[{ }^{35} \mathrm{~S}\right]$-dimethylsulfone and/or $\left[{ }^{35} \mathrm{~S}\right]$-sulfate) should be disposed of as liquid waste and should not contain any volatiles at that stage. Decontamination of glassware should be undertaken for 7 days with the radioisotope methods before transferring into $5 \%(\mathrm{v} / \mathrm{v})$ Decon 90 or equivalent for a further $24 \mathrm{~h}$, and then one should proceed following local rules for disposal of the isotope in solution as dimethylsulfone.

In this section we give the basic semimicromethod for carbon-13 and micromethod for carbon-14, as well as adaptations for sulfur-34 and sulfur-35. Carbon-11 can also be used, which decays via $\beta+$ decay and electron capture, with energies of $0.96 \mathrm{MeV}$ or $1.98 \mathrm{MeV}$, respectively, and a half-life of $20.3 \mathrm{~min}$. [ $\left.{ }^{11} \mathrm{C}\right]$-carbon dioxide can be obtained through proton bombardment of nitrogen-14 at very high specific activities (c. $100 \mathrm{GCi} / \mathrm{mol})$ - this necessitates working in very small volumes in a full-sealed reaction system. This is then reduced with lithium aluminum hydride to yield $\left[{ }^{11} \mathrm{C}\right]$-methanol, which is reacted with hydroiodic acid to produce the $\left[{ }^{11} \mathrm{C}\right]$ methyl iodide required for the synthesis of $\left[{ }^{11} \mathrm{CU}\right]-\mathrm{DMS}$, as detailed by Marazano et al. (1977). Bombardment is done in a cyclotron, which necessitates collaboration for most workers - Moses (1964) and Aronoff (1956) cover useful methodologies for nanoscale radiochemistry that may be of use for carbon-11 work.

Glassware should be washed very thoroughly in advance followed by $24 \mathrm{~h}$ in $10 \%(v / v)$ nitric acid, washing with glass-distilled water (not "MilliQ," etc. which sometimes contain low levels of $\mathrm{C}_{1}$ compounds that can disrupt reactions) and drying in an oven. Joints should be lightly greased with high-vacuum grease.

In any syntheses that use natural abundance sodium sulfide nonahydrate, crystals should be cleaned of sulfur oxyacids before use. Filter paper is mounted in a Büchner funnel in a flask, set up for filtration at the pump. With the vacuum already turned on, the crystals are shaken directly onto the filter paper from a new, unopened jar of $\geq 99.5 \%$ purity $\mathrm{Na}_{2} \mathrm{~S} \cdot 9 \mathrm{H}_{2} \mathrm{O} .100 \mathrm{~mL}$ ice-cold glass-distilled water is rapidly poured over the crystals and is immediately removed with the vacuum. Crystals are blotted completely dry with filter paper and are quickly weighed into the reaction vessel. If it is intended to wait before using them, flush the flask with argon, seal with a glass stopper, and store at $-20{ }^{\circ} \mathrm{C}$. 


\subsubsection{Synthesis of $\left[{ }^{13} \mathrm{C}_{\mathrm{U}}\right]$-Dimethylsulfide}

$\left[{ }^{13} \mathrm{C}_{\mathrm{U}}\right]$-DMS $(M=64.13 \mathrm{Da})$ has a density of $0.873 \mathrm{~g} / \mathrm{mL}$, melts at $-98{ }^{\circ} \mathrm{C}$, and boils at $38{ }^{\circ} \mathrm{C}$. It can be prepared in a single working day from sodium sulfide and $\left[{ }^{13} \mathrm{C}\right]$-methyl iodide, which is readily available. The cost of synthesis of about $1 \mathrm{~g}$ of $\left[{ }^{13} \mathrm{C}_{\mathrm{U}}\right]$-DMS in terms of reagents (not including those used in the work-up) is (May 2018) £346 (US\$468, €395), which is significantly more economical than paying a chemical supply company to undertake it as a custom synthesis. The following methodology was developed by one of us (RB) and is adapted from McAllan et al. (1951) and Beerli and Borschberg (1991). Since publication of the original summary method (Neufeld et al. 2008), we have added more efficient purification methods and thus report this here.

$6.4 \mathrm{~g} \mathrm{Na}_{2} \mathrm{~S} \cdot 9 \mathrm{H}_{2} \mathrm{O}(26.4 \mathrm{mmol})$ is dissolved in $6.4 \mathrm{~mL}$ glass-distilled water in a two-neck $25 \mathrm{~mL}$ round-bottomed flask in the fume hood, which is stirred vigorously with a glass stirring "flea" and a magnetic stirrer, and is closed with a glass stopper at the top neck. The side neck has a thermometer held in a ground-glass adaptor and which reaches the liquid in the flask. Once fully dissolved, the flask is surrounded with an ice water bath and the contents are stirred until $0{ }^{\circ} \mathrm{C}$. The stopper is replaced with a $10 \mathrm{~mL}$ pressure-equalizing addition funnel, to which $2.18 \mathrm{~mL}(5.00 \mathrm{~g}$, $35 \mathrm{mmol}$ ) $\left[{ }^{13} \mathrm{C}\right]$-methyl iodide is added. The latter is of $\geq 99 \%$ isotopic and chemical purity and is usually supplied with a length of copper wire as a stabilizer - care must be taken not to transfer this to the addition funnel. Over $30 \mathrm{~min}$, the $\left[{ }^{13} \mathrm{C}\right]$-methyl iodide is added at intervals, taking care to maintain the temperature at $0{ }^{\circ} \mathrm{C}-\mathrm{a}$ little ammonium chloride can be added to the ice bath if needed, but care should be taken not to cool the flask contents too far below the specified temperature. The addition funnel is removed and replaced with a glass stopper, and the flask contents are stirred very rapidly for $4 \mathrm{~h}$, taking care to keep the reaction temperature as specified. After this, the ice bath is replaced with fresh wet ice to cool the flask contents for $15 \mathrm{~min}$, and the flask is then opened, and $1 \mathrm{~mL} 2.5 \mathrm{M} \mathrm{NaOH}$ is added, with stirring, followed by $1 \mathrm{~mL} 0.1 \mathrm{M} \mathrm{Na}_{2} \mathrm{~S}_{2} \mathrm{O}_{3}$, which lyses any excess methyl iodide into methanol and elementary iodine, the latter being reduced to iodide, such that it will not contaminate the product. The flask is moved to a water bath and is topped with a ported Hickman still-head in turn topped with a dry-ice trap that has the lower tubing olive sealed off with Viton ${ }^{\circledR}$ tubing and a clamp, so that it can be used as a cold-finger. The trap is charged with dry-ice, and the water bath is heated to maintain the flask contents, with stirring, at $30-35^{\circ} \mathrm{C}$. Over $1-2 \mathrm{~h}$, the Hickman head will fill with essentially pure $\left[{ }^{13} \mathrm{C}_{\mathrm{U}}\right]$-DMS, from which it can be removed with a Pasteur pipette into a serum bottle. The theoretical yield is $1.12 \mathrm{~g}(17.5 \mathrm{mmol}, 1.28 \mathrm{~mL})$, and while $88 \%$ yields of $0.98 \mathrm{~g}(15.4 \mathrm{mmol}, 1.12 \mathrm{~mL})$ have been reported (Beerli and Borschberg 1991), removal of all of the product from the Hickman head directly is difficult - washing out the head with sterile glass-distilled water will obtain a solution of $\left[{ }^{13} \mathrm{C}_{\mathrm{U}}\right]$-DMS which can easily be quantified and stored in a serum bottle under argon and used when more dilute samples are needed, so as not to waste it we have used this solution in stable-isotope probing ecology studies (Neufeld et al. 2008), for example. Alternatively, a very small volume of water can be used, and liquid product can be separated from it in a separatory funnel, but there are few solvents fully immiscible with the product. If desired, the neat product can be 
purified further by shaking with twice with 5 volumes of glass-distilled water and then twice with 5 volumes of $10 \%(w / v) \mathrm{NaOH}$, followed again with 5 volumes of water. The product can then be dried with anhydrous calcium chloride and is stored in non-actinic glass under argon at $-20^{\circ} \mathrm{C}$.

\subsubsection{Synthesis of $\left[{ }^{14} C_{U}\right]$-Dimethylsulfide}

Carbon-14 has a half-life of 5,730 years and decays by $\beta$ - emission at $0.156 \mathrm{MeV}$, which is a "soft beta" emission that is easy to handle. Given the long half-life, both starting materials and the product can be stored indefinitely without appreciable decay, but radiolysis should be taken into account if stored for decades before use - it may be prudent to repurify.

$\left[{ }^{14} \mathrm{C}\right]$-methyl iodide at specific activities of $50-60 \mathrm{mCi} / \mathrm{mmol}$ in $5 \mathrm{mCi}(c .8 \mu \mathrm{L}$, users should refer to batch-specific analyses) aliquots in break-seal flasks from American Radiolabeled Chemicals, Inc. These can be opened using a Schlenk line, or a heavy glass stirring "flea" can be put into the neck and the neck sealed with a greased Suba-Seal held in place with a cable tie. The flask is frozen in liquid nitrogen to condense the product and is then shaken to break the glass seal. $2.19 \mathrm{~mL}$ ( $35 \mathrm{mmol}, 4.97 \mathrm{~g}$ ) natural abundance (" $\left[{ }^{12} \mathrm{C}\right]-$ " hereafter) methyl iodide is injected into the flask, which is allowed to warm to room temperature to equilibrate the label into the liquid, giving a final specific activity of about $0.14 \mathrm{mCi} / \mathrm{mmol}-$ if higher specific activities are needed, the synthesis can be scaled down to a micro synthesis, which we describe herein - if using the semimicro synthesis, the method for $\left[{ }^{13} \mathrm{C}_{\mathrm{U}}\right]$ DMS can be adapted accordingly. For micro synthesis, $10 \mathrm{mCi}\left[{ }^{14} \mathrm{C}\right]$-methyl iodide is dissolved as described above in $7 \mathrm{mmol}(0.44 \mathrm{~mL})\left[{ }^{12} \mathrm{C}\right]$-methyl iodide to give a specific activity of $1.42 \mathrm{mCi} / \mathrm{mmol}$, thus $2.84 \mathrm{mCi} / \mathrm{mmol}$ in the final product of the reaction - given for most physiological work or for microautoradiography, dilution to about $1 \mu \mathrm{Ci}$ in $5 \mathrm{mM}$ DMS is sufficient; this specific activity is sufficient. If higher specific activities are needed, the isotope should be diluted less and the reaction scaled down further.

All synthetic work should be done in accordance with local rules. If working with $>5 \mathrm{mCi}$ of carbon-14, it is usual to use $10 \mathrm{~mm}$ Perspex shielding and detection badges. To a $5 \mathrm{~mL}$ conical reaction vial, add $1.28 \mathrm{~g} \mathrm{Na}_{2} \mathrm{~S} \cdot 9 \mathrm{H}_{2} \mathrm{O}(5.28 \mathrm{mmol})$ and $1.28 \mathrm{~mL}$ glass-distilled water, and stir with a magnetic, PTFE-coated "spin vane," with the lid of the vial in place until the entire solid material has dissolved. Meanwhile, withdraw the $\left[{ }^{14} \mathrm{C}\right]$-labeled methyl iodide (about $0.45 \mathrm{~mL}$ ) from the flask using a $0.5 \mathrm{~mL}$ glass syringe and a long needle. Transfer the reaction vial into a crystallizing dish on top of the stirrer and fill with an ice water slush. Replace the lid of the vial with one ported for a micro Liebig condenser in the reflux orientation and run cold water through it from the bottom up. Place a thermometer port onto the top and lower a thermometer down into the sulfide solution, taking care to stay above the stirring vane. Prepare a drying column to connect to the top of the condenser with anhydrous calcium chloride, but do not connect it. Maintaining the temperature of the liquid in the vial at $0{ }^{\circ} \mathrm{C}$, slowly inject the $\left[{ }^{14} \mathrm{C}\right]$-methyl iodide using a long needle so that it can be added down the condenser directly into the liquid - this should be added slowly with vigorous stirring, over $30 \mathrm{~min}$, and the syringe and needle then rinsed with the liquid in the reaction vial. Put the drying column onto the 
top of the condenser and maintain the system at $0{ }^{\circ} \mathrm{C}$ for $4 \mathrm{~h}$, ensuring the condenser stays cold. At the end of the reaction, transfer the reaction vial into a crystallizing dish of water on a stirring hot plate. Add $0.2 \mathrm{~mL} 2.5 \mathrm{M} \mathrm{NaOH}$ and then $0.2 \mathrm{~mL} 0.1 \mathrm{M}$ $\mathrm{Na}_{2} \mathrm{~S}_{2} \mathrm{O}_{3}$. Attach a ported microscale Hickman still-head, topped with dry-ice-loaded microscale cold-finger as described in the carbon-13 method, above, to the top of the reaction vial. Load a thermometer down the still-head into the region just above the liquid and heat the water bath until the thermometer reads $35-38^{\circ} \mathrm{C}$ - by keeping the temperature at this level for $1-2 \mathrm{~h}$, the product is distilled into the Hickman head. A theoretical yield would be $0.22 \mathrm{~g}(3.5 \mathrm{mmol}, 0.26 \mathrm{~mL})$, with specific activity of $2.84 \mathrm{mCi} / \mathrm{mmol}$ - but for the more typical $88 \%$ yield, $0.20 \mathrm{~g}(3.1 \mathrm{mmol}, 0.05 \mathrm{~mL})$ at the same specific activity is obtained. The neat product is removed from the Hickman head via the port and is added to a $3 \mathrm{~mL}$ reaction vial containing $1.5 \mathrm{~mL}$ $10 \%(w / v) \mathrm{NaOH}$, which is capped and shaken and then cooled in an ice water to reduce pressure and to allow the layers to separate. The entire mixture is drawn into a filter Pasteur pipette of suitable volume (made by pushing a tiny ball of glass wool down into the tip of a Pasteur pipette using a length of stiff wire), and the heavy (aqueous) phase $\left[{ }^{14} \mathrm{C}_{\mathrm{U}}\right]$-DMS is released into a second, clean vial, and the aqueous phase is disposed of as low-level waste. This process is repeated three times and then repeated using water in place of $\mathrm{NaOH}$ three more times. The product is then dried over a small amount of anhydrous calcium chloride and is then filtered through a glass Pasteur pipette stuffed with a loose plug of glass wool into the beginning of the constriction and is collected in a $1 \mathrm{~mL}$ reaction vial, which is flushed lightly with argon and sealed. Alternatively, it can be cooled to $-50{ }^{\circ} \mathrm{C}$ and dispensed into glass ampoule blanks which are flushed quickly with argon and rapidly sealed using two blowtorches positioned so that their flames cross. $\left[{ }^{14} \mathrm{C}_{\mathrm{U}}\right]$-DMS should be stored at $-20{ }^{\circ} \mathrm{C}$ under $10 \mathrm{~mm}$ thick Perspex - it is worth noting that even in well-sealed reaction vials, the product may escape, so serum bottles or ampoules are preferential. The specific activity can be confirmed by liquid scintillation counting in Ultima Gold $^{\mathrm{TM}}$ XR liquid scintillation cocktail (Perkin-Elmer) or, equivalent, in a glass scintillation vial, using $1 \mu \mathrm{L}$ in $10 \mathrm{~mL}$ cocktail, and counting for replicates of $1 \mathrm{~h}$ after leaving for $24 \mathrm{~h}$ in the dark beforehand. Counts should be normalized against quench curves made using nitromethane as the quench and a suitable carbon-14 standard such as $\left[{ }^{14} \mathrm{C}_{1}\right]$-acetate or $\left[{ }^{14} \mathrm{C}_{\mathrm{U}}\right]$-glucose. The cost of this synthesis, pace the work-up, and isotopic determination is (May 2018) £2,750 (US\$3,709, €3,118).

\subsubsection{Synthesis of $\left[{ }^{34} S\right]$-Dimethylsulfide}

Sulfur-34 is a stable isotope suited to some isotope-fractionation experiments with various groups of the Bacteria. It can also be used as a tracer but sensitivity is not as high as with a radioisotope.

Sodium $\left[{ }^{34} \mathrm{~S}\right]$-sulfide is not currently (May 2018) commercially available, but $\left[{ }^{34} \mathrm{~S}_{\mathrm{U}}\right]$-cyclooctasulfur (i.e., $\mathrm{S}_{8}$ elementary sulfur) can be obtained from SigmaAldrich at 90 at.\% as a custom-packaged product. This can be reduced using solvated electrons generated by elementary sodium in anhydrous ammonia:

$$
2 \mathrm{Na}+\mathrm{S} \rightarrow \mathrm{Na}_{2} \mathrm{~S}
$$


This procedure is beyond the scope of this chapter and requires a skilled radiochemist, but to prepare the necessary $26.4 \mathrm{mmol}$ sodium sulfide, $0.90 \mathrm{~g}\left[{ }^{34} \mathrm{~S}_{\mathrm{U}}\right]$ cyclooctasulfur $(26.4 \mathrm{mmol} \mathrm{S})$ is reacted with at least $1.21 \mathrm{~g}(52.8 \mathrm{mmol})$ elementary sodium - though allowing for loss during work-up etc., it is probably prudent to double this. The carbon-13 synthesis (above) can then be followed using the purified sodium $\left[{ }^{34} \mathrm{~S}\right]$-sulfide product and $\left[{ }^{12} \mathrm{C}\right]$-methyl iodide - this will yield a similar amount in moles of product, but of $M=64.00 \mathrm{Da}$, at 90 at. $\%$, so the overall $M$ is 63.81 Da.

\subsubsection{Synthesis of $\left[{ }^{35} \mathrm{~S}\right]$-Dimethylsulfide}

Sulfur-35 has a half-life of 87.51 days (about 3 months) and decays by $\beta$ - emission at $0.167 \mathrm{MeV}$, which is a "soft beta" emission that is easy to handle. Given the short half-life, both starting materials and the product decay - a large specific activity should be ordered and work conducted immediately and the product used with rapidity. The decay product is chlorine-35, which means decay results in lysis of the product, thus repurification every 3 months is needed, and the decay should be taken into account when calculating how much to use in experiments. After 9 months (three half-lives), the $\left[{ }^{35} \mathrm{~S}\right]$-DMS should be disposed of as low-level waste.

Sodium $\left[{ }^{35} \mathrm{~S}\right]$-sulfide of $50-100 \mathrm{mCi} / \mathrm{mmol}$ can be obtained from American Radiolabeled Chemicals, Inc., as a solid in $5 \mathrm{mCi}$ batches (c. 8-16 mg, users should refer to batch-specific analyses). Using the washing procedures described above, a solution of normal isotopic $\mathrm{Na}_{2} \mathrm{~S} \cdot 9 \mathrm{H}_{2} \mathrm{O}$ is prepared $(6.4 \mathrm{~g}$ in $6.4 \mathrm{~mL}$ water), and a few $\mathrm{mL}$ are added to the vial containing the isotope, which is then sealed and incubated on a roller for $30 \mathrm{~min}$, before tipping into a clean $50 \mathrm{~mL}$ round-bottomed flask. The remaining stock solution is then used to wash the entire labeled compound out of the original container - as evidenced with a sensitive Geiger-Müller counter. This can be used with $\left[{ }^{12} \mathrm{C}\right]$-methyl iodide per the carbon-13 protocol, above, with quantification done according to that for carbon-14, to produce a theoretical yield of $1.14 \mathrm{~g}(17.5 \mathrm{mmol})$, but $88 \%$ yields of $1.00 \mathrm{~g}(15.4 \mathrm{mmol})$ are more likely in practice - this being of about $0.29 \mathrm{mCi} / \mathrm{mmol}$. If higher specific activities are needed, raise the concentration of the label and/or use the microscale method outlined for carbon14, above. The cost (May 2018) of preparation of about $1 \mathrm{~g}$ of $0.29 \mathrm{mCi} / \mathrm{mmol}$ product - excluding work-up and determination costs - is about $£ 1,750$ (US\$2,363, $€ 1,984)$. This is an economical labeling method, albeit a short-lived label; thus a full work plan should be ready for use as soon as it is synthesized.

\subsubsection{Cognate Preparation of $\left[{ }^{13} C_{u}\right]-,\left[{ }^{14} C_{u}\right]-,\left[{ }^{34} S\right]-$, and $\left[{ }^{35} S\right]-$ Dimethylsulfoxide}

Herein we give procedures based on Beerli and Borschberg (1991) with amounts in mmol rather than $\mathrm{g}$ or $\mathrm{mL}$ as the various labels would all have to be given, and the user will need to scale anyway to the amount obtained from the previous procedures. Workers thus need to convert to mass, etc. remembering to use the correct $M$ for the product and not that of the standard unlabeled compound!

After preparation of the relevant DMS and purifying, it should be introduced (23.2 $\mathrm{mmol})$ into a round-bottomed flask containing a glass-coated "flea" (scaledown to a microprocedure accordingly if need be) with three necks, one sealed with 
a glass stopper, one with a thermometer capable of working at $-100{ }^{\circ} \mathrm{C}$, and a third left open. The flask is cooled in dry-ice-acetone slush atop a magnetic stirrer until the contents are $-78{ }^{\circ} \mathrm{C} .13 \mathrm{mmol} 96 \% \mathrm{~m}$-chlorobenzoic acid in $35 \mathrm{~mL}$ diethyl ether is added via a pressure-equalizing addition funnel slowly (added to the open neck) over $90 \mathrm{~min}$ with stirring. The flask contents are brought to room temperature, and $0.018 \mathrm{mmol} \mathrm{Na}_{2} \mathrm{~S}_{2} \mathrm{O}_{3}$ and $14.0 \mathrm{mmol} \mathrm{K}_{2} \mathrm{CO}_{3}$ are added with stirring, which is continued for $16 \mathrm{~h}$. Contents of the flask are filtered at the pump and the filtrate washed with 3 vol dichloromethane. The filtrate is distilled in a Kugelrohr short-path distillation apparatus at 0.13 atm with the cage at $170{ }^{\circ} \mathrm{C}$, which yields about $10 \mathrm{mmol}$ labeled DMSO, which should be dried over $4 \AA$ molecular sieve and stored under argon at $-20{ }^{\circ} \mathrm{C}$.

\subsubsection{Cognate Preparation of $\left[{ }^{13} \mathrm{C}_{U}\right]-,\left[{ }^{14} \mathrm{C}_{\mathrm{U}}\right]-,\left[{ }^{34} \mathrm{~S}\right]-$, and $\left[{ }^{35} \mathrm{~S}\right]-$ Dimethylsulfone}

Per the previous section, we use mmol herein rather than mass, etc. These procedures are based on McAllan et al. (1951). Suitable methods for recrystallization of very small amounts of (radiolabeled) solid material are found in Aronoff (1956).

$23.2 \mathrm{mmol}$ of the purified, labeled DMS is dissolved in $47 \mathrm{~mL}$ glacial acetic acid in a three-neck flask cooled in ice and equipped with a glass-coated "flea," on a magnetic stirrer. $24 \mathrm{~mL}$ "100 volume" hydrogen peroxide is added from a pressureequalizing addition funnel with rapid stirring, and with the other flask necks closed, slowly over an hour. The flask is removed from the ice bath and a Dimroth or Friedrichs condenser attached to the middle neck (the others are closed), topped with a drying column of calcium chloride. The condenser is cooled with water and the flask incubated at room temperature with stirring for $48 \mathrm{~h}$, before refluxing for $4 \mathrm{~h}$. The flask is transferred to a rotary evaporator and heated under reduced pressure to drive off the acetic acid, leaving behind the solid $\mathrm{DMSO}_{2}$, which is recrystallized to constant melting point from diethyl ether, then dried in vacuo, and stored at $-20{ }^{\circ} \mathrm{C}$.

\subsubsection{Synthesis of Labeled Methanethiol}

The most common means of synthesis of MT is from methanol and hydrogen sulfide using aluminia or reduced molybdenum sulfide catalysts. Since $\left[{ }^{13} \mathrm{C}\right]$-methanol and $\left[{ }^{14} \mathrm{C}\right]$-methanol are readily available and hydrogen $\left[{ }^{35} \mathrm{~S}\right]$-sulfide and hydrogen $\left[{ }^{34} \mathrm{~S}\right]$-sulfide can both synthesized from labeled elementary sulfur (summarized in Sect. 2.3.3), the synthesis of all labeled versions of MT alone or with duel labeling is possible; however, the synthetic methods are complex, require fastidious levels of dryness and anoxia, and thus are beyond the means of most biologists - collaboration with a skilled radiochemist is probably needed, who should consult Paskach et al. (2002) and Roberts (2000) for practical details. Kaufmann (2015) details means to synthesize methanethiol from DMS, which could be used for cognate preparation from DMS labeled as described herein. 


\subsubsection{Cognate Preparation of $\left[{ }^{13} \mathrm{C}_{U}\right]-,\left[{ }^{14} \mathrm{C}_{\mathrm{U}}\right]-,\left[{ }^{34} \mathrm{~S}\right]-$, and $\left[{ }^{35} \mathrm{~S}\right]-$ Dimethyldisulfide}

Oxidation of MT with air or with elementary iodine will yield DMDS:

$$
\begin{gathered}
2 \mathrm{CH}_{3} \mathrm{SH}+[\mathrm{O}] \rightarrow\left(\mathrm{CH}_{3}\right)_{2} \mathrm{~S}_{2}+\mathrm{H}_{2} \mathrm{O} \\
2 \mathrm{CH}_{3} \mathrm{SH}+\mathrm{I}_{2} \rightarrow\left(\mathrm{CH}_{3}\right)_{2} \mathrm{~S}_{2}+2 \mathrm{HI}
\end{gathered}
$$

Isotopically labeled DMDS can thus be synthesized from any labeled MT, using molecular oxygen in the presence of $\mathrm{Fe}^{3+}$ or $\mathrm{Cu}^{2+}$, or catalyzed by the use of ultraviolet light (Koval' 1994). Hydrogen peroxide, ferric chloride (Field 1977), elementary iodine (Bock and Rittmeyer 1992), and potassium ferricyanide (Koval' 1993 ) are also widely used in these reactions. Koval' (1994) reviews the methodologies, which should be adapted for use with labeled MT at an appropriate scale.

\subsubsection{Cognate Preparation of $\left[{ }^{13} \mathrm{C}_{\mathrm{U}}\right]-,\left[{ }^{14} \mathrm{C}_{\mathrm{U}}\right]-,\left[{ }^{34} \mathrm{~S}\right]-$, and $\left[{ }^{35} \mathrm{~S}\right]-$ Methanesulfonate}

Labeled sodium methanesulfonate can be prepared by neutralizing labeled methanesulfonic acid, which is made by oxidizing appropriately labeled MT using $m$-chloroperoxybenzoic acid, which is described for microscale synthesis by Feil et al. (1988).

\section{Pathways of $\mathrm{C}_{1}$ Organosulfur Compound Metabolism}

In this section we cover the core metabolic pathways that have been identified for $\mathrm{C}_{1}$ organosulfur compounds. These compounds can be assimilated as carbon or sulfur sources -for the former, they are usually dissimilated to formaldehyde or formate (methylotrophs) or carbon dioxide (autotrophs) first; for the latter they are oxidized to dimethylsulfone $\left(\mathrm{DMSO}_{2}\right)$ and then to methanesulfonate (MSA) before assimilating at the level of sulfite - this is usually in heterotrophs under sulfur starvation. DMSO can additionally be used as a respiratory terminal electron acceptor in some Bacteria. When utilized as a carbon source, the carbon assimilation is via the serine cycle (Alphaproteobacteria) or the Quayle pathway (ribulose monophosphate pathway, Gammaproteobacteria and Betaproteobacteria). In contrast, the autotrophs dissimilate the carbon to carbon dioxide and could assimilate it via any one of the six known bacterial carbon dioxide fixation pathways - though thus far, all known examples use the Calvin-Benson-Bassham (CBB) cycle. There is increasing evidence from sulfur-35 work that the sulfur moiety of DMS can be assimilated into biomass, though given the abundance of sulfate in most environments, it is hard to see a circumstance in which this would be an evolutionary advantage, pace in the example of organisms using every possible assimilation source at the same time to beat the competition - "thiovidity," if one were to need a term to describe using every source of sulfur in an environment at the same time (from Gr. neut. n. $\theta \varepsilon \tilde{l}_{o \nu}$ (theîon), sulfur, brimstone, transliterated into Latin as thium; L. fem. n. aviditas, greed; thiovidity, sulfur-greed), rather than switching from sulfate or thiosulfate to 
using, e.g., DMS because there was no thio/sulfate left, as is in the case in many organisms in which expression of these enzymes has been demonstrated (Kertesz 1996; van der Ploeg et al. 1996). In this section, we summarize the various catabolic pathways that have been described, with enzymes covered in the next section.

It is worth noting that several DMS monooxygenases, several DSMO monooxygenases, several DMSO reductases, etc. have been purified and characterized. There are clearly distinct classes - the dissimilatory enzymes used to convert these compounds into, e.g., formaldehyde for assimilation as a carbon source and the assimilatory enzymes used when these compounds act as sulfur sources, in which they are ultimately oxidized to sulfite, and the respiratory enzymes as well. We have introduced the convention herein of referring to them as such for clarity, since these enzymes are functionally distinct, e.g., the DMS monooxygenase DmoAB sensu Boden et al. (2011b) and De Bont et al. (1981) catalyzes

$$
\left(\mathrm{CH}_{3}\right)_{2} \mathrm{~S}+\mathrm{O}_{2}+\mathrm{NADH}+\mathrm{H}^{+} \rightarrow \mathrm{CH}_{3} \mathrm{SH}+\mathrm{HCHO}+\mathrm{NAD}^{+}+\mathrm{H}_{2} \mathrm{O}
$$

and is involved in the use of DMS as a carbon and energy source in Hyphomicrobium spp. and Thiobacillus spp., whereas the DMS monooxygenase DsoABCDEF of Horinouchi et al. $(1997,1999)$ catalyzes both the oxidation of DMS and DMSO:

$$
\begin{gathered}
\left(\mathrm{CH}_{3}\right)_{2} \mathrm{~S}+\mathrm{O}_{2}+\mathrm{NADH}+\mathrm{H}^{+} \rightarrow\left(\mathrm{CH}_{3}\right)_{2} \mathrm{SO}+\mathrm{H}_{2} \mathrm{O}+\mathrm{NAD}^{+} \\
\left(\mathrm{CH}_{3}\right)_{2} \mathrm{SO}+\mathrm{O}_{2}+\mathrm{NADH}+\mathrm{H}^{+} \rightarrow\left(\mathrm{CH}_{3}\right)_{2} \mathrm{SO}_{2}+\mathrm{H}_{2} \mathrm{O}+\mathrm{NAD}^{+}
\end{gathered}
$$

and is involved in the use of DMS and DMSO as sulfur sources in Acinetobacter sp. 20B. We discuss the nature of many of these enzymes and whether they are bona fide monooxygenases.

The chemical series of DMS, DMSO, and $\mathrm{DSMO}_{2}$ in terms of level of oxidation means that their catabolic and sulfur-assimilatory pathways overlap. DMSO can also be used as a terminal electron acceptor, resulting in the formation of DMS - $\mathrm{DSMO}_{2}$ probably can as well but this has not yet been observed - though we anticipate that it occurs. The $S$-oxidation of DMS and DMSO to form DMSO and $\mathrm{DMSO}_{2}$, respectively, without any oxidation of the carbon occurs in chemolithoheterotrophs such as Sagittula stellata (Boden et al. 2011a), whereas full mineralization into inorganic sulfur oxyanions and carbon dioxide occurs in both chemolithoautotrophs such as Thiobacillus thioparus (Smith 1988) and in methylotrophs such as Hyphomicrobium spp. (Suylen et al. 1996) - but there is a hinterland in which "internal" chemolithoheterotrophy occurs (Boden et al. 2010 used this term, but we have since favored "endochemolithoheterotrophy" (Boden and Hutt 2018a, b), in the sense that the electron donor (thiosulfate) is formed endogenously during DMS catabolism, in contrast to "exochemolithoheterotrophy" which would be, e.g., growth on glucose with exogenously supplied thiosulfate). Endochemolithoheterotrophy has been observed in Methylophaga spp. (De Zwart 1997; De Zwart et al. 1996; Boden et al. 2010) and in Xanthobacter spp. (Padden 1997; Padden et al. 1997, 1998) the latter are wont to growing endochemolithoheterotrophically and autotrophically 
at the same time on some substrates, which represents the maximal use of trophic modes at the same time - we have elsewhere (Boden and Hutt 2018b) proposed the term "voracotrophy" for this circumstance.

While DMS, DMDS, and MT are toxic, with organisms tolerating only concentrations $<5 \mathrm{mM}$ or so in usual batch cultures, DMSO, $\mathrm{DMSO}_{2}$, and MSA are non-toxic and thus better tolerated - organisms will tolerate DMSO to relatively high concentrations $(0.2 \mathrm{M})$ as it is not very toxic, though interestingly in Hyphomicrobium denitrificans WU-K217, it grew best at 75-150 mM, growing poorly at both low and high concentrations - possibly owing to osmotic effects (Murakami-Nitta et al. 2002). H. denitrificans WU-K217 was isolated on $20 \mathrm{mM}$ DMSO as the sole carbon and energy source, but the precise source is not clearly reported. This indicates that for DMSO-isolated organisms, testing growth in this range of concentrations is important as it could lead to higher specific growth yields and thus easier work, particularly with protein or mRNA.

\subsection{De Bont Pathway}

De Bont et al. (1981) isolated Hyphomicrobium sp. S from enrichment cultures on $13 \mathrm{mM}$ DMSO as the sole carbon source, inoculated with soil, incubated under air at $30{ }^{\circ} \mathrm{C}$. The organism assimilated carbon using the serine cycle and performed a stoichiometric conversion of DMS or DMSO sulfur to sulfate. The pathway of dissimilation was proposed to be

$$
\mathrm{DMSO} \rightarrow \mathrm{DMS} \rightarrow \mathrm{MT} \rightarrow \mathrm{S}^{2-} \rightarrow ? \rightarrow \mathrm{SO}_{4}{ }^{2-}
$$

with two formaldehyde molecules being liberated in the second and third steps. Given that the first step occurred in the absence of air but the second did not, an NADH-dependent DMSO reductase and NADH-dependent DMS monooxygenase were implicated for these steps, followed by a methanethiol oxidase (evidenced by hydrogen peroxide production at this step and catalase activity). Formaldehyde could be assimilated via the serine cycle or dissimilated via formaldehyde dehydrogenase and formate dehydrogenase (both yielding NADH) to carbon dioxide.

\subsection{Visscher-Taylor Pathway}

Visscher and Taylor (1993a) studied two strains that they designated as members of the genus Thiobacillus and that were isolated in previous studies. Visscher isolated (Visscher et al. 1991) Thiobacillus sp. T5 from enrichment cultures on 1.3 mM DMS as the sole carbon and energy source, incubated under air at $25^{\circ} \mathrm{C}$, inoculated with pieces of a microbial mat collected from the West Frisian island of Texel (Tessel) in the North Sea off the Netherlands. Visscher and Taylor (1993b) isolated Thiobacillus sp. ASN-1 from enrichment cultures on $0.5 \mathrm{mM}$ DMS as the sole carbon and energy 
source, with nitrate as the terminal electron acceptor, inoculated with sediment from a cordgrass (Spartina L.) marsh on Sapelo Island, GA, USA.

The two putative Thiobacillus isolates (NB: since strain ASN-1 could be grown on multicarbon compounds, it is not a true Thiobacillus) were studied and were found to have two different pathways for DMS catabolism. Thiobacillus sp. T5 catabolized DMS via the De Bont pathway (see Sect. 3.1), but Thiobacillus sp. ASN-1 had an oxygen-independent first step, in which a putative DMS methyltransferase (correctly, a demethylase) transferred a methyl group from DMS onto a carrier, which was then oxidized to formate. The methanethiol remaining was oxidized via a methanethiol oxidase to sulfide, which was then oxidized to sulfate, presumably via the same mechanisms as in the De Bont pathway.

\subsection{Smith-Kelly Pathway}

Smith (1988) examined two strains of Thiobacillus thioparus (identities verified by Boden et al. 2012), viz., Thiobacillus thioparus E6 and Thiobacillus thioparus Tk-m - the latter was also examined by Kanagawa and Kelly (1986). T. thioparus E6 (= DSM 5369) was isolated by Smith from an enrichment culture on $0.5 \mathrm{mM}$ dimethyldisulfide (DMDS) under air, inoculated with pond water from Coventry, UK. T. thioparus Tk-m (= DSM 5368) was isolated by Kanagawa and Mikami (1989) from a mixed culture (Tk-1), originally obtained from enrichment culture on $19 \mathrm{mM}$ O,O-dimethylphosphorodithioate (Kanagawa et al. 1982; Kanagawa and Kelly 1986).

Just as De Bont et al. (1981) had noted that the dissimilation of DMSO and DMS was stepwise, such that the latter was an intermediate of the dissimilation of the former, Smith (1988) observed that dimethyldisulfide (DMDS) and MT share a similar relation, such that the De Bont pathway proceeds:

$$
\mathrm{DMSO} \rightarrow \mathrm{DMS} \rightarrow \mathrm{MT} \rightarrow \mathrm{S}^{2-} \rightarrow ? \rightarrow \mathrm{SO}_{4}{ }^{2-}
$$

and the Smith-Kelly pathway proceeds:

$$
\mathrm{DMDS} \rightarrow 2 \mathrm{MT} \rightarrow 2 \mathrm{~S}^{2-} \rightarrow ? \rightarrow 2 \mathrm{SO}_{4}{ }^{2-}
$$

with an NADH-dependent DMDS reductase catalyzing the first reaction:

$$
\left(\mathrm{CH}_{3}\right)_{2} \mathrm{~S}_{2}+\mathrm{NADH}+\mathrm{H}^{+} \rightarrow 2 \mathrm{CH}_{3} \mathrm{SH}+\mathrm{NAD}^{+}
$$

and the subsequent oxidation of MT proceeds per the De Bont pathway, with the carbon oxidized to carbon dioxide for autotrophic assimilation. Smith and Kelly (1988) proposed that thiosulfate and/or tetrathionate may be intermediates in the oxidation of sulfide to sulfate. 


\subsection{De Zwart-Kuenen Pathway}

De Zwart (1997) and De Zwart et al. (1996) isolated Methylophaga sulfidovorans LMD $95.210^{\mathrm{T}}$ from enrichment cultures inoculated with marine mat samples collected in 1993 from an intertidal estuarine region off Roelshoek, Zeeland, Netherlands. Cultures were supplemented with $1 \mathrm{mM}$ DMS as the sole carbon and energy source. DMS metabolism in M. sulfidovorans was similar to the VisscherTaylor and De Bont pathways, but rather than sulfate being the end product, thiosulfate was formed by unknown means:

$$
2 \mathrm{DMS} \rightarrow 2 \mathrm{MT} \rightarrow 2 \mathrm{~S}^{2-} \rightarrow ? \rightarrow \mathrm{S}_{2} \mathrm{O}_{3}{ }^{2-}
$$

Exochemolithoheterotrophic growth at the expense of exogenous sulfide was observed, in common with other Methylophaga spp. (cf. Sect. 3.5).

\subsection{Boden-Kelly Pathway}

Boden et al. (2010) studied the type strain of Methylophaga thiooxydans (DSM $22068^{\mathrm{T}}$ ), which was previously isolated (as Methylophaga sp. DMS010) from enrichment cultures inoculated with four pooled, non-axenic cultures of Emiliania huxleyi (Lohm.) Hay and Mohler, isolated variously from the Sargasso Sea (obtained in 1987 and 1960), English Channel (1957), and South Pacific (1991). These cultures were grown on $0.05 \mathrm{mM}$ DMS as the sole carbon and energy source (Schäfer 2007).

Similar to the Visscher-Taylor pathway, $M$. thiooxydans has an oxygenindependent oxidation of DMS to MT via a DMS demethylase and then proceeds per the De Bont pathway as far as hydrogen sulfide, which is disproportionated by a sulfite reductase (EC 1.8.1.2) and sulfide-cytochrome $c$ reductase (EC 1.8.2.3) to yield sulfite and elementary sulfur, respectively, which then combine chemically via the Suzuki and Silver (1966) reaction to thiosulfate (Boden et al. 2010). This is then oxidized to tetrathionate via a cytochrome $c$-linked thiosulfate dehydrogenase (EC 1.8.2.2) - electrons from this terminal step are used to generate proton-motive force $(\Delta p)$ and thus ATP, which was demonstrated in whole cells and was inhibited by the uncoupling agents 2,4-dinitrophenol, carbonyl cyanide $m$-chlorophenylhydrazone (CCCP), and carbonyl cyanide $p$-(trifluoromethoxy)phenylhydrazone (FCCP). The DMS oxidation pathway in M. thiooxydans is effectively that of M. sulfidovorans "plus one" as it has an additional step, and of course the route of thiosulfate formation is resolved:

$$
8 \mathrm{DMS} \rightarrow 8 \mathrm{MT} \rightarrow 8 \mathrm{~S}^{2-} \rightarrow 4 \mathrm{~S}^{0}+4 \mathrm{SO}_{3}{ }^{2-} \rightarrow 4 \mathrm{~S}_{2} \mathrm{O}_{3}{ }^{2-} \rightarrow 2 \mathrm{~S}_{4} \mathrm{O}_{6}{ }^{2-}
$$

This study (Boden et al. 2010) was the first report of the formation of a polythionate from an organosulfur precursor and the first report of the coupling of DMS and organosulfur compound cycling in the environment to the cycling of 
polythionates and reduced sulfur species, which are then metabolized to sulfate by ubiquitous marine chemolithoautotrophs such as Thiomicrospira, Thiomicrorhabdus, Hydrogenovibrio, Guyparkeria, and Halothiobacillus spp. This additional (vs. Methylophaga sulfidovorans) terminal step oxidizing thiosulfate to tetrathionate via the ubiquitous cytochrome $c$-linked thiosulfate dehydrogenase (Denkmann et al. 2012) gives the organism an ecological "leg up" in two ways:

\section{Endochemolithoheterotrophic growth on DMS rather than heterotrophic growth on DMS}

i.e., chemolithoheterotrophic growth at the expense of endogenously produced thiosulfate, rather than growth on DMS without energetic gain in this additional step - this leads to higher specific molar growth yields $\left(Y_{\mathrm{MAX}}\right)$ and is thus a clear evolutionary advantage. See also Boden and Hutt (2018a) for a detailed discussion of this.

\section{Production of a toxic end product}

Tetrathionate is toxic to many Gammaproteobacteria, for example, and production of it will no doubt inhibit or kill the competition (Palumbo and Alford 1970; Boden et al. 2010).

Evidence from inhibitor studies suggested that the DMS demethylase (EC 2.1.1.x) was corrinoid linked, since it was inhibited strongly by $n$-iodopropionate (cf. Brot and Weissbach 1965) and $n$-butyl iodide in the dark. It was also inhibited by ethyl vinyl sulfide (EVS), mersal, and arsenite - the former is a suicide inhibitor of $S$-adenosylmethionine thioester $S$ methyltransferase, in which it acts as an alternative cofactor, forming the methyl ethyl vinyl sulfonium anion, which binds to amino acids in the active site (Warner and Hoffman 1996). It is known that corrinoid cofactors are bound by vicinal thiol groups in the active site of enzymes (Hogenkamp 1968); thus inhibition by arsenite - which binds strongly to thiol groups - would support a corrinoid demethylase.

\subsection{Padden-Wood Pathway}

Xanthobacter tagetidis DSM $11105^{\mathrm{T}}$ was isolated from compost surrounding the rootball of a Tagetes sp., through enrichment culture on thiophene-2-carboxylate (T2C) as the sole carbon and energy source, and, in common with other Xanthobacter spp., grows chemolithoautotrophically on thiosulfate and methylotrophically on methanol, MT, DMS, etc. but only aerobically. When resting cell suspensions were incubated with $5 \mathrm{mM}$ MT under air or under nitrogen, the former produced hydrogen sulfide, in line with the presence of an MT oxidase, but the latter produced carbon dioxide and methane over about $3 \mathrm{~h}$, but no sulfide was detected all intermediates and end products were determined using GC-MS, so are likely to be valid data - which Padden (1997) determined as 


$$
4 \mathrm{CH}_{3} \mathrm{SH}+3 \mathrm{H}_{2} \mathrm{O} \rightarrow 3 \mathrm{CH}_{4}+\mathrm{HCO}_{3}^{-}+4 \mathrm{HS}^{-}+5 \mathrm{H}^{+}
$$

which was similar to pathways used in methanogenic Archaea and thus somewhat surprising in one of the Bacteria (Zinder and Brock 1978). This hydrolysis of MT in a member of the Bacteria has not been observed elsewhere and in some ways does not make biological sense, since in vivo, Xanthobacter spp. cannot oxidize methane; thus the methane produced would be wasted, and only the bicarbonate $(25 \%$ of the MT carbon oxidized) would be assimilated. Padden (1997) felt that this was not a biological step and instead represented something caused by a paucity of oxygen in these incubations and may represent a malfunctioning enzyme; however, methane is produced by some Alphaproteobacteria during the acquisition of phosphate from methylphosphonate via a complex pathway of proteins encoded by the phn operon, which we summarize (Yao et al. 2016; Grossart et al. 2011; Karl et al. 2008):

$\mathrm{CH}_{3} \mathrm{PO}_{3} \mathrm{H}_{2}+\mathrm{ATP}+\mathrm{H}_{2} \mathrm{O} \rightarrow \mathrm{CH}_{4}+5$-phospho- $\alpha$-D-ribose-1,2-cyclicphosphate + pyrophosphate + adenine

As such, Padden could have potentially observed an as yet unknown sulfur acquisition pathway, in which MT was being oxidized purely for the sulfide moiety.

DMS was metabolized in samples incubated without oxygen as far as sulfide; thus it was proposed that MT oxidase does not participate and that a "double" DMS demethylase per that of Visscher and Taylor (1993a, b) but acting on both carbons was used, with all carbon assimilated at the level of carbon dioxide (Padden 1997; Padden et al. 1997, 1998):

$$
\begin{gathered}
\left(\mathrm{CH}_{3}\right)_{2} \mathrm{~S}+2 \mathrm{XH} \rightarrow 2 \mathrm{XCH}_{3}+\mathrm{H}_{2} \mathrm{~S} \\
2 \mathrm{XCH}_{3}+4 \mathrm{H}_{2} \mathrm{O} \rightarrow 2 \mathrm{CO}_{2}+2 \mathrm{XH}+6 \mathrm{H}^{+}
\end{gathered}
$$

Note that the Padden-Wood pathway does not proceed from DMS to MT as is the case in the de Bont pathway, Boden-Kelly pathway, Smith-Kelly pathway, and Visscher-Taylor pathway - but may represent an alternative use of the DMS demethylase for CBB cycle uptake rather than uptake at the level of formaldehyde by the serine cycle or Quayle pathway.

\subsection{Borodina-Wood pathway}

Borodina (2002) and Borodina et al. (2000, 2002) note that the pathway of $\mathrm{DMSO}_{2}$ catabolism in Hyphomicrobium, Arthrobacter, and Pseudarthrobacter species examined was the De Bont pathway of DMS catabolism plus a DMSO reductase and a $\mathrm{DSMO}_{2}$ reductase:

$$
\left(\mathrm{CH}_{3}\right)_{2} \mathrm{SO}_{2} \rightarrow\left(\mathrm{CH}_{3}\right) 2 \mathrm{SO} \rightarrow\left(\mathrm{CH}_{3}\right)_{2} \mathrm{~S} \rightarrow \mathrm{MT} \rightarrow \mathrm{S}^{2-} \rightarrow ? \rightarrow \mathrm{SO}_{4}{ }^{2-}
$$


The organisms containing the Borodina-Wood pathway were all soil isolates from garden soil obtained from Radford-Semele, Warwickshire, UK, from enrichment cultures on $20 \mathrm{mM} \mathrm{DMSO}$.

\subsection{Kino-Wicht pathway}

In Hyphomicrobium sp. WU-OM3, $\mathrm{DMSO}_{2}$ was oxidized via unknown steps to methanesulfonate (MSA) - which we presume are the assimilatory $\mathrm{DMSO}_{2}$ monooxygenase of Wicht (2016), which was then in turn oxidized to sulfate (Kino et al. 2004). DMS was not produced as an intermediate in this pathway.

For sulfur assimilation, the assimilatory $\mathrm{DMSO}_{2}$ monooxygenase (SnfG, EC 1.14.14.35) is used by Pseudomonas putida DS1 under sulfur limitation (Wicht 2016), which is an FMN-dependent monooxygenase similar to DMS monooxygenase (Boden et al. 2011b). SnfG catalyzes the oxidation of $\mathrm{DMSO}_{2}$ to methanesulfinate (MSiA):

$$
\left(\mathrm{CH}_{3}\right)_{2} \mathrm{SO}_{2}+\mathrm{FMNH}_{2}+\mathrm{O}_{2} \rightarrow\left(\mathrm{CH}_{3}\right) \mathrm{SO}_{2}{ }^{-}+\mathrm{HCHO}+\mathrm{H}_{2} \mathrm{O}
$$

The MSiA $\left(\left(\mathrm{CH}_{3}\right) \mathrm{SO}_{2}{ }^{-}\right)$is then chemically oxidized to methanesulfonate (MSA):

$$
\left(\mathrm{CH}_{3}\right) \mathrm{SO}_{2}^{-} \rightarrow\left(\mathrm{CH}_{3}\right) \mathrm{SO}_{3}^{-}
$$

The MSA is then further oxidized to formaldehyde and sulfite, the latter of which is assimilated.

In Hyphomicrobium spp., which have the ability to assimilate formaldehyde as a carbon and energy source, it is likely that the sulfur assimilation pathway can also lead to carbon assimilation and thus growth - the terminal oxidation of sulfite to sulfate was probably a means of stock control and dealing with too much sulfite, which can be toxic, or the spontaneous oxidation of sulfite to sulfate in the presence of oxygen. The Kino-Wicht pathway is an unusual hybrid situation, which may be entirely a laboratory artifact of a Hyphomicrobium sp. growing under sulfate-limited growth, forcing it to use $\mathrm{DMSO}_{2}$ as a sulfur source and co-assimilating the carbon; alternatively, it could represent an additional assimilation pathway from carbon that is used when both carbon and sulfur are needed: when sulfate is present, carbon is assimilated via the Borodina-Wood pathway, but if sulfate is absent, the Kino-Wicht pathway allows both sulfur and carbon to be assimilated together.

\subsection{Koch-Dahl Pathway}

Very recently, Koch and Dahl (2018) have studied DMS dissimilation in Hyphomicrobium denitrificans $\mathrm{X}^{\mathrm{T}}$. Like other Hyphomicrobium spp. (De Bont et al. 1981; Borodina 2002; Borodina et al. 2000, 2002; Boden et al. 2011b), the 
organism oxidized DMS to sulfate - as is the fate in the majority of DMS oxidizing Alphaproteobacteria that are in culture. The key finding of this study was in confirming the pathway of the downstream oxidation of sulfide produced by MT oxidase. The authors found that a heterodisulfide reductase (Hdr, EC 1.8.98.1) was expressed during methylotrophic growth on DMS and demonstrated that it is involved in the oxidation of sulfide, which proceeded identically to the De Bont pathway until hydrosulfide $\left(\mathrm{HS}^{-}\right)$was produced. This then interacted with hydrosulfite to yield thiosulfate, either fully chemically as observed by Boden et al. (2010) or by direct action of enzymes from the Kelly-Friedrich thiosulfateoxidizing multienzyme system, viz., SoxXA and SoxB (the precise nature of this coupling was not entirely clear in the paper). Thiosulfate could be oxidized by a cytochrome-linked thiosulfate dehydrogenase (TsdA, Denkmann et al. 2012) to tetrathionate; alternatively, the thiosulfate could be oxidized further. The sulfonatesulfur of thiosulfate could be oxidized to sulfate by SoxXA and SoxB, while the sulfane-sulfur was bound to SoxYZ, from which it could be transferred via the sulfur carrier protein TusA (Dahl et al. 2011) to the Hdr complex, which oxidized the sulfane-sulfur originating from thiosulfate, now in the form of the "outer" sulfur of a bound disulfane $\left(-\mathrm{SS}^{-}\right)$group on TusA, to hydrosulfite $\left(\mathrm{HSO}_{3}{ }^{-}\right)$, which was recycled to react with more hydrosulfide to yield thiosulfate. The authors also noted that the organism could be grown in the presence of exogenous thiosulfate, as was also the case with other Hyphomicrobium spp. and Methylophaga spp. - in this work, thiosulfate was oxidized to tetrathionate stoichiometrically, which was not further oxidized - there was no sufficient data to demonstrate the coupling of this to the generation of $\Delta p$ and thus robustly demonstrate exochemolithoheterotrophy (cf. Boden and Hutt (2018a) for the requirements needed to robustly demonstrate this trait) or to demonstrate that the oxidation of thiosulfate from DMS by TsdA was endochemolithoheterotrophy, but it is likely to be the case. The fate of sulfur from DMS was shown to be sulfate in this study, but since tetrathionate is an alternative fate in theory, it could be that the organism produces the latter as an "overflow" reaction when the pool of thiosulfate in the cell becomes too large or does so only when the energy demands require it. The work of Koch and Dahl (2018) probably provides the end of the De Bont pathway and Borodina-Wood pathways, though it would need demonstrating during growth on DMSO and $\mathrm{DMSO}_{2}$, of course, and demonstrates a further difference between the metabolism of DMS in the Alphaproteobacteria from the Beta- and Gammaproteobacteria.

\section{Enzymology of $C_{1}$ Organosulfur Compound Metabolism}

In this section we have given revised enzyme nomenclature where the evidence is clear that multiple separate enzymes (functionally and evolutionarily) grouped under one umbrella name and/or Enzyme Commission (EC) number at present. Figure 1 accompanies this section and gives a summary of the canon of $\mathrm{C}_{1}$ organosulfur research over the last 40 or so years. We give summaries of enzyme assay methodologies where they have been published and are demonstrably not subject to false positives, etc. 


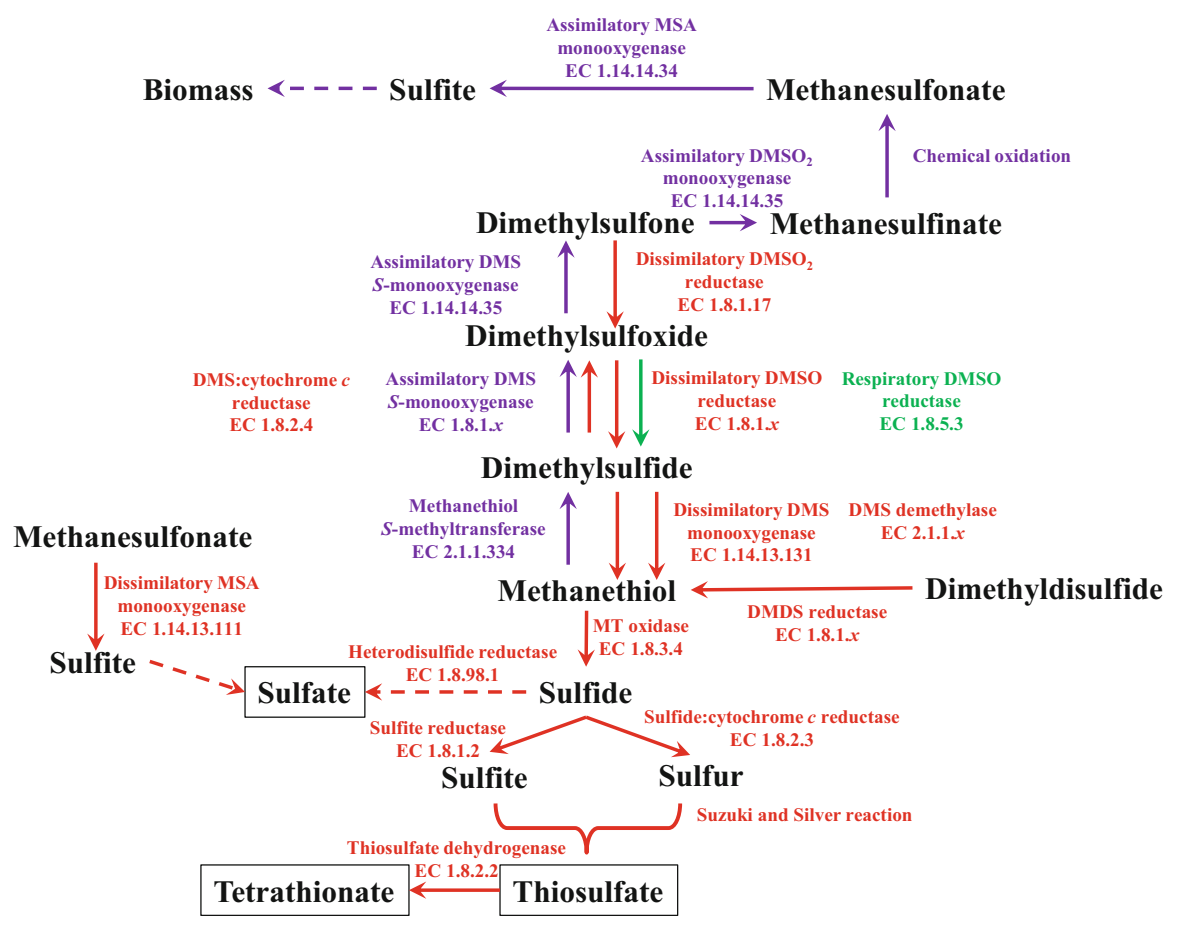

Fig. 1 Summary of the canon of literature concerning $C_{1}$ organosulfur compound metabolism. Enzyme names and Enzyme Commission (E.C.) numbers are those given in the text of this chapter, where we have recommended changes where multiple enzymes have historically been grouped together - E.C. numbers ending in " $x$ " are where an E.C. number has yet to be assigned to this enzyme, but we indicate the classification herein. Only sulfur intermediates are shown; formaldehyde, etc. are omitted for clarity. Species in boxes are known end products of dissimilatory metabolism. Arrows indicate enzymes - dashes arrows are multiple or unknown steps. Red, dissimilation; violet, assimilation; green, respiration; gray, role unclear

\subsection{Dissimilatory Dimethylsulfide Monooxygenase (EC 1.14.13.131)}

As described by De Bont et al. (1981), the overall reaction mechanism of dissimilatory dimethylsulfide monooxygenase (EC 1.14.13.131) is

$$
\left(\mathrm{CH}_{3}\right)_{2} \mathrm{~S}+\mathrm{O}_{2}+\mathrm{NADH}+\mathrm{H}^{+} \rightarrow \mathrm{CH}_{3} \mathrm{SH}+\mathrm{HCHO}+\mathrm{NAD}^{+}+\mathrm{H}_{2} \mathrm{O}
$$

The enzyme was first purified by Boden et al. (2011b) from Hyphomicrobium sulfonivorans $\mathrm{S}^{\mathrm{T}}$ (Borodina et al. 2002) grown on $\mathrm{DMSO}_{2}$ as the sole carbon source, which is dissimilated via DMSO and DMS, and was previously shown to produce one peptide band in common in $\mathrm{DMSO}_{2}$ - and DMS-grown cells, which was previously suspected to be the DMS monooxygenase (Borodina 2002; Borodina et al. 2000, 2002), which was demonstrated by enzyme activity in cells grown both 
ways. In the work of Boden et al. (2011b), the enzyme was purified from cells grown in a $\mathrm{DMSO}_{2}$-limited chemostat $\left(D=0.03 \mathrm{~h}^{-1}\right.$, with $\left.40 \mathrm{mM} \mathrm{DMSO} \mathrm{DS}_{2}\right)$ using a mix of gel filtration and affinity chromatography. The purified enzyme was found to be $72 \mathrm{kDa}$ in size, comprising two subunits, DmoA (53 kDa) and DmoB (19 kDa) - the former is an $\mathrm{FMNH}_{2}$-dependent DMS monooxygenase and the latter is an NADHdependent flavin oxidoreductase - an overall structure in common with those of the bacterial luciferase family - the DmoA subunit was shown to be related to the pristinamycin IIA synthase (SnaA, Streptomyces sp. DSM 40338), nitrilotriacetate monooxygenase (NtaA, EC 1.14.14.10, Aminobacter aminovorans), EDTA monooxygenase (EmoA, EC 1.14.14.10, EC, Mesorhizobium sp. BNC1), alkanesulfonate monooxygenase (SsuD, EC 1.14.14.5, Pseudomonas putida), and dibenzothiophenesulfone monooxygenase (DszA, EC 1.14.14.21, Rhodococcus sp. IGTS8). The enzyme is stimulated by $\mathrm{Fe}(\mathrm{II})$ and $\mathrm{Mg}$ (II) ions, and if the metals of the enzyme were depleted with EDTA, $\mathrm{Fe}(\mathrm{II})$ and $\mathrm{Mg}$ (II) ions restored activity. It was inhibited strongly by umbelliferone, $\mathrm{Hg}(\mathrm{II}), \mathrm{Cd}(\mathrm{II})$, and $\mathrm{Pb}$ (II) ions and was wholly dependent on NADH and FMN rather than NADPH or other flavins.

DMS monooxygenase is assayed at the optimum growth temperature of the organism by filling a $1 \mathrm{~mL}$ optical quartz cuvette with $0.85 \mathrm{~mL} 20 \mathrm{mM}$ PIPES$\mathrm{HCl} \mathrm{pH}$ 7.4, supplemented with $1 \mathrm{mM} \mathrm{NADH}, 3 \mu \mathrm{M}$ FMN, $5 \mu \mathrm{M}$ dithiothreitol, and $5 \mu \mathrm{M}$ ferrous ammonium sulfate. $50 \mu \mathrm{L}$ cell-free extract is added, and the endogenous rate of NADH oxidation is monitored at $340 \mathrm{~nm}\left(\varepsilon=6.2 \mathrm{mM}^{-1} \mathrm{~cm}^{-1}\right) .100 \mu \mathrm{L}$ $10 \mathrm{mM}$ DMS solution is then added and the rate of DMS-dependent NADH oxidation is determined.

\subsection{Assimilatory Dimethylsulfide S-Monooxygenase (EC 1.8.1.x)}

This enzyme (originally named "DMS monooxygenase," but this is ambiguous this enzyme specifically oxidizes the sulfur moiety; thus we have recommended the above name) has been characterized by recombinant expression from Acinetobacter sp. 20B (Horinouchi et al. 1997, 1999) and catalyzes the oxidation of DMS to DMSO and also that of DMSO to $\mathrm{DMSO}_{2}$, in the assimilation of sulfur from these species - the $\mathrm{DMSO}_{2}$ monooxygenase of Wicht (2016) discussed later in this chapter is the next step in the assimilation of sulfur:

$$
\mathrm{MT} \rightarrow \mathrm{DMS} \rightarrow \mathrm{DMSO} \rightarrow \mathrm{DMSO}_{2} \rightarrow \mathrm{MSA} \rightarrow \text { sulfite } \rightarrow \text { biomass }
$$

The enzyme catalyzes the reactions

$$
\begin{gathered}
\left(\mathrm{CH}_{3}\right)_{2} \mathrm{~S}+\mathrm{O}_{2}+\mathrm{NADH}+\mathrm{H}^{+} \rightarrow\left(\mathrm{CH}_{3}\right) \mathrm{SO}+\mathrm{H}_{2} \mathrm{O}+\mathrm{NAD}^{+} \\
\left(\mathrm{CH}_{3}\right) \mathrm{SO}+\mathrm{O}_{2}+\mathrm{NADH}+\mathrm{H}^{+} \rightarrow\left(\mathrm{CH}_{3}\right) \mathrm{SO}_{2}+\mathrm{H}_{2} \mathrm{O}+\mathrm{NAD}^{+}
\end{gathered}
$$

It is a multicomponent monooxygenase (DsoABCEDF), which has very high sequence homology to the $\mathrm{NAD}(\mathrm{P}) \mathrm{H}$-linked phenol 2-monooxygenases (EC 1.14.13.7, MopKLMNOP or DmpKLMNOP), which are also termed phenol 
hydrolases, which are soluble diiron monooxygenases (SDIMO), a family that includes the soluble methane monooxygenase (sMMO, MmoXYZBCD, EC 1.14.13.25) involved in obligate methanotrophs such as Methylococcus capsulatus Bath during copper starvation, or in facultative methanotrophs such as Methylocella spp. as their only primary methane oxidizing enzyme (Smith and Murrell 2011). As such, this enzyme has no functional, structural, or evolutionary relationship with the DMS monooxygenase EC 1.14.13.131, and thus we recommend it is moved to a separate EC number (EC 1.8.1.x), with the name "assimilatory dimethylsulfide $S$-monooxygenase" to better describe physiological function and the action of the enzyme, removing confusion.

The enzyme is assayed in a discontinuous manner in $10 \mathrm{~mL}$ serum bottles containing $3 \mathrm{~mL}$ PIPES-HCl pH 7.4 supplemented with $1 \mathrm{mM}$ DMS and $1 \mathrm{mM}$ $\mathrm{NAD}(\mathrm{P}) \mathrm{H}$, to which $0.1 \mathrm{~mL}$ cell-free extract is added. The concentrations of DMS and DMSO are both monitored, with the former disappearing and the latter appearing. This should be done over $5 \mathrm{~min}$ or so, as in longer incubations, the DMSO will oxidize to $\mathrm{DMSO}_{2}$. For rapidity, the assay could be conducted in the barrel of a water-jacketed glass syringe, with contents ejected into tubes held in ice-salt at intervals to stop the reaction for assay of products and substrate.

It is worth noting that the enzyme can be qualitatively assayed using the oxidation of indole to indigo (Horinouchi et al. 1997), which is not catalyzed by the dissimilatory DMS monooxygenase (Boden, unpublished data). This could be useful in screening organisms or looking for induction during chemostat experiments, in the same way that the oxidation of naphthalene to 1-naphthol is used for sMMO.

It is also worth noting that the oxidation of DMSO to $\mathrm{DMSO}_{2}$ has been observed in many Eukarya (e.g., Williams et al. 1965) and could proceed via an evolutionarily related enzyme, though this has not been studied to date.

\subsection{Dissimilatory Dimethylsulfide Demethylase (EC 2.1.1.x)}

Thus far, this enzyme has not been purified or identified in proteomic or transcriptomic studies (Boden et al. 2011b) and can only be detected as the oxygenindependent oxidation of DMS to MT:

$$
\left(\mathrm{CH}_{3}\right)_{2} \mathrm{~S}+\mathrm{X}-\mathrm{H} \rightarrow \mathrm{CH}_{3} \mathrm{SH}+\mathrm{X}-\mathrm{CH}_{3}
$$

where $X$ is some manner of corrinoid cofactor (Boden et al. 2010).

The enzyme is assayed in $10 \mathrm{~mL}$ serum bottles with butyl rubber stoppers coated with PTFE. $1 \mathrm{~mL}$ cell-free extract is introduced into vials and gassed with argon for $15 \mathrm{~min}$ to exclude air. $0.1 \mathrm{~mL} 10 \mathrm{mM}$ DMS in $0.2 \mathrm{M}$ PIPES-HCl pH 7.4 is added, to give a final concentration of $1 \mathrm{mM}$ DMS. Bottles are incubated with shaking at the optimum growth temperature of the organism, and DMS and MT are both determined at intervals $(5 \mathrm{~min}$ ) using methods given elsewhere in this chapter. A control using boiled cell-free extract or formaldehyde-fixed cell-free extract is important to include, as is one with water in place of biomass. 
It is worth noting that an as-yet-hypothetical DMS hydrolase (discussed in Boden et al. 2010) could also give a similar result, but methanol would be detectable as well as MT, and the dissimilation of DMS by living cells could be inhibited by cyclopropanol, which inhibits methanol dehydrogenase (EC 1.1.2.7).

\subsection{Methanethiol Oxidase (EC 1.8.3.4)}

This enzyme has been purified from organisms including Thiobacillus thioparus Tk-m (Gould and Kanagawa 1992), Hyphomicrobium sp. EG (Suylen 1988; Suylen et al. 1987), and Rhodococcus rhodochrous (Kim et al. 2000).

$$
\mathrm{CH}_{3} \mathrm{SH}+\mathrm{H}_{2} \mathrm{O}+\mathrm{O}_{2} \rightarrow \mathrm{HCHO}+\mathrm{H}_{2} \mathrm{O}_{2}+\mathrm{H}_{2} \mathrm{~S}
$$

The enzyme is inhibited by diphenyleneiodonium in M. thiooxydans (Boden et al. 2010), a common oxidase inhibitor, since it reacts with the hydrogen peroxide produced by the enzyme to form a radical that attacks enzyme cofactors (O'Donnell et al. 1993). It is around 40-50 kDa, varying between organisms, and was inhibited by ammonium ions and by cyanide in Hyphomicrobium sp. EG (Suylen 1988) and by solutes in $R$. rhodochrous (Kim et al. 2000). In Hyphomicrobium methylovorum VS (Eyice et al. 2018), the monomer, MtoX, was reported at $46.2 \mathrm{kDa}$, found in homotetramers of $185 \mathrm{kDa}$. The same study reported the $m$ toX gene in M. thiooxydans, Ruegeria pomeroyi DSM $15171^{\mathrm{T}}$, and various T. thioparus strains, including T. thioparus Tk-m from which it was purified previously (Gould and Kanagawa 1992). The MtoX homotetramer contains a tryptophan tryptophanylquinone (TTQ) prosthetic group and four $\mathrm{Ca}$ and two $\mathrm{Cu}$ atoms per MtoX monomer.

The enzyme can be assayed using discontinuous methods only and by quantification of MT decreasing and (crucially) sulfide, formaldehyde, or hydrogen peroxide increasing. We have found that the Cline (1969) method for sulfide is very effective. Formaldehyde determination by the Hantzsch reaction (Nash 1953) is very prone to interferences in biological systems (Cinti and Thal 1977) - we have observed that even MilliQ deionized water will give a false-positive result, presumably from glycine traces - and in the laboratory in which $\mathrm{C}_{1}$ compounds and methylotrophs are handled, this is more of an issue. We have made use of 4-amino-3-hydrazino-5-mercapto-1,2,4-triazole (Purpald ${ }^{\circledR}$ ), which, in alkaline solution, gives a rapid reaction with formaldehyde to yield a deep purple adduct that is readily determined at $550 \mathrm{~nm}$ against calibration curves (Quesenberry and Lee 1996). For determination of hydrogen peroxide, the titanium sulfate (Eisenberg 1943) and 4-aminoantipyridine with phenol (Zhou et al. 2006) methods are both effective colorimetric methods that are easy and rapid.

To assay the enzyme, $10 \mathrm{~mL}$ serum bottles containing small glass stirring "fleas" are filled with $5 \mathrm{~mL}$ of a $1 \mathrm{mM}$ solution of MT in water, which is thoroughly degassed beforehand (see later in this chapter re: handling of MT) to prevent dimerization. $0.5 \mathrm{~mL} \quad 0.1 \mathrm{M}$ PIPES-HCl $\mathrm{pH} 7.4$ is added, followed by 
$0.05-0.10 \mathrm{~mL}$ cell-free extract. After rapid stirring on a magnetic stirrer (in a water bath at the optimal growth temperature), samples are withdrawn using a syringe. Keeping the needle in situ and using a tap or valve is convenient. Those samples are rapidly added to serum bottles held in an ice-salt slush at $-5{ }^{\circ} \mathrm{C}$ to halt biological activity (lids replaced after adding the solution). This is continued at a range of time points over 5-10 min, and then each bottle thawed if necessary and from it aliquots carefully measured for analytical determinations. It is prudent to add zinc acetate to aliquots for sulfide determination as it "fixes" the sulfide in a form that will still react for assay but is no longer labile.

\subsection{Methanethiol S-methyltransferase (EC 2.1.1.334)}

This enzyme has recently been identified in Pseudomonas spp. that can assimilate $\mathrm{C}_{1}$ sulfur compounds - it catalyzes the reaction

$$
\begin{aligned}
& \mathrm{CH}_{3} \mathrm{SH}+\mathrm{S}-\text { adenosyl }-\mathrm{L}-\text { methionine } \\
& \quad \rightarrow+\left(\mathrm{CH}_{3}\right)_{2} \mathrm{~S}+\mathrm{S}-\text { adenosyl - homocysteine }
\end{aligned}
$$

producing DMS from MT. It comprises a single subunit, MddA, which is membraneassociated. Homologues of the $m d d A$ gene were found in many taxa from the Proteobacteria to the Actinobacteria, and it was found to be extremely abundant in soil metagenome studies (Carrión et al. 2015), which proposed that this is the dominant route of DMS production in soils.

\subsection{Dimethylsulfide-Cytochrome $c$ Reductase (EC 1.8.2.4)}

Also known as "dimethylsulfide dehydrogenase," this very well-characterized enzyme was purified from Rhodovulum sulfidophilum SH1 and catalyzes

$$
\left(\mathrm{CH}_{3}\right)_{2} \mathrm{~S}+2 \text { cyt } c_{2(\text { ox })}+\mathrm{H}_{2} \mathrm{O} \rightarrow\left(\mathrm{CH}_{3}\right) \mathrm{SO}+2 \text { cyt } \mathrm{c}_{2(\text { red })}+2 \mathrm{H}^{+}
$$

It is a molybdoprotein related to the respiratory DMSO reductases (EC 1.8.5.3), dissimilatory DMSO reductases (EC 1.8.1.x), and trimethylamine $N$-oxide reductases (TorA, EC 1.7.2.3) and comprises the subunits DdhABC (McDevitt et al. $2002 \mathrm{a}, \mathrm{b})$. This Rhodovulum sulfidophilum strain is reported to grow autotrophically, using the DMS as the electron donor (Hanlon et al. 1994), and is found in the periplasm. 


\subsection{Respiratory Dimethylsulfoxide Reductase (EC 1.8.5.3)}

Two DMSO reductases exist, both currently united as EC 1.8.5.3, even though this level of hierarchy relates to quinol donors - which is the case in the respiratory form - and not NAD(P)H per the dissimilatory form.

The respiratory DMSO reductase (EC 1.8.5.3) comprises the DmsABC subunits, wherein DmsA is functionally and structurally very similar to the dissimilatory DMSO reductase (cf. next section); DmsB is an iron-sulfur protein, and DmsC is a transmembrane unit that anchors the enzyme and accepts electrons from the quinol pool, which are then passed through DmsB to DmsA and on to DMSO (Bilous et al. 1988; Bilous and Weiner 1985):

$$
\left(\mathrm{CH}_{3}\right)_{2} \mathrm{SO}+2 \mathrm{QH}_{2} \rightarrow\left(\mathrm{CH}_{3}\right)_{2} \mathrm{~S}+2 \mathrm{Q}+\mathrm{H}_{2} \mathrm{O}
$$

DMSO is thus used as a terminal electron acceptor by members of the Enterobacteriaceae, for example, with Escherichia coli and so on producing DMS as their respiratory end product. This is an analogous process to the use of trimethylamine $\mathrm{N}$-oxide (TMAO) as their terminal electron acceptor and releasing trimethylamine, using trimethylamine $N$-oxide reductase (TorECA, EC 1.7.2.3):

$$
\left(\mathrm{CH}_{3}\right)_{3} \mathrm{NO}+2 \mathrm{Cyt} c_{(\text {red })}+2 \mathrm{H}^{+} \rightarrow\left(\mathrm{CH}_{3}\right)_{3} \mathrm{~N}+2 \mathrm{Cyt} c_{(\text {ox })} \mathrm{H}_{2} \mathrm{O}
$$

Both TMAO reductase and DMSO reductase are molybdoproteins, with molybdopterin cofactors bound in TorA and DmsA, respectively (Zhang et al. 2008).

\subsection{Dissimilatory Dimethylsulfoxide Reductase (EC 1.8.1.x)}

We propose the separation of this enzyme from EC 1.8.5.3 since it is coupled to $\mathrm{NAD}(\mathrm{P}) \mathrm{H}$ and not to quinols. While the dissimilatory enzyme is comprised of only one subunit versus the respiratory one, it is very similar to the DmsA subunit of the latter. As the DmsC membrane anchor and DmsB iron-sulfur protein are absent in the dissimilatory form, it is soluble and found in the periplasm rather than being membrane bound per the respiratory form. In Hyphomicrobium spp. it catalyzes the dissimilation of DMSO to DMS at the expense of $\mathrm{NAD}(\mathrm{P}) \mathrm{H}$ :

$$
\left(\mathrm{CH}_{3}\right)_{2} \mathrm{SO}+\mathrm{NAD}(\mathrm{P}) \mathrm{H}+\mathrm{H}^{+} \rightarrow\left(\mathrm{CH}_{3}\right)_{2} \mathrm{~S}+\mathrm{H}_{2} \mathrm{O}+\mathrm{NAD}(\mathrm{P})^{+}
$$

Borodina et al. (2000, 2002) identified DMSO reductase in extracts of $\mathrm{DMSO}_{2}$ grown $H$. sulfonivorans $\mathrm{S1}^{\mathrm{T}}$, Arthrobacter methylotrophus DSM $14008^{\mathrm{T}}$, and Pseudarthrobacter sulfonivorans DSM $14002^{\mathrm{T}}$, in terms of both enzyme activity and through Western blots using antibodies raised to the respiratory form, which of course shares DmsA.

The enzyme is assayed in a Thunberg cell (Ahlgren 1925) containing $1 \mathrm{~mL}$ water, $0.15 \mathrm{~mL}$ 1.0 M PIPES-HCl pH 7.6, and $50 \mu \mathrm{L}$ cell-free extract in the main chamber, which is then deoxygenated by bubbling with argon for $15 \mathrm{~min}$. The side arm is filled 
with $0.3 \mathrm{~mL} 50 \mathrm{mM}$ DMSO and $1.5 \mathrm{~mL} 2 \mathrm{mM}$ methyl viologen (MV, reduced with dithionite) in $50 \mathrm{mM}$ PIPES-HCl pH 7.6 added to the main chamber. The whole apparatus is then evacuated for $10 \mathrm{~min}$ and is then sealed. Endogenous MV oxidation is monitored at $600 \mathrm{~nm}\left(\varepsilon=1.13 \mathrm{mM}^{-1} \mathrm{~cm}^{-1}\right)$, and then the contents of the side arm are added to the main chamber, and the enzyme activity is monitored for 5-10 min. Activity is expressed in nmol methyl viologen oxidized $\min ^{-1}$ (mg protein) ${ }^{-1}$.

\subsection{Dissimilatory Dimethylsulfone Reductase (EC 1.8.1.17)}

This enzyme has not been purified thus far but has been demonstrated in terms of enzyme activity in Hyphomicrobium, Arthrobacter, and Pseudarthrobacter spp. (Borodina 2002; Borodina et al. 2000, 2002). Much like the DMSO reductase, it catalyzes the NADH-dependent dissimilation of $\mathrm{DMSO}_{2}$ to DMSO:

$$
\left(\mathrm{CH}_{3}\right) \mathrm{SO}_{2}+\mathrm{NADH}+\mathrm{H}^{+} \rightarrow\left(\mathrm{CH}_{3}\right)_{2} \mathrm{SO}+\mathrm{H}_{2} \mathrm{O}+\mathrm{NAD}^{+}
$$

Very little is known about this enzyme, but it can be easily assayed using the same methodology as that we have given for dissimilatory DMSO reductase but using $0.3 \mathrm{~mL} 50 \mathrm{mM} \mathrm{DMSO}_{2}$ in lieu of DMSO in the side arm of the Thunberg cell.

\subsection{Assimilatory Dimethylsulfone Monooxygenase (EC 1.14.14.35), Assimilatory Methanesulfonate Monooxygenase (EC 1.14.14.34), and Dissimilatory Methanesulfonate Monooxygenase (EC 1.14.13.111)}

Wicht (2016) demonstrated this enzyme in Pseudomonas putida DS1 based on previous work by Endoh et al. (2003a, b, 2005) that uses methylated sulfur species as sulfur sources. The enzyme comprises the catalytic subunit ( $\mathrm{SnfG}, 40.3 \mathrm{kDa}$ ), which is an FMN-dependent monooxygenase similar to the large subunit of dissimilatory DMS monooxygenase (DmoAB, EC 14.13.131, Boden et al., 2011b), and which is coupled in vitro to an NADH-dependent FMN reductase (SnfF, 20.3 kDa), as an SnfGF heterodimer of $60.6 \mathrm{kDa}$ which is distinct both in size and sequence to the c. $72 \mathrm{kDa}$ DmoAB (Fig. 2). This is part of the sulfur assimilation pathway from DMS, DMSO, $\mathrm{DMSO}_{2}$, and methanesulfonate that is used during sulfur starvation in, e.g., Pseudomonas spp., with DMS and DMSO being oxidized to $\mathrm{DMSO}_{2}$ (stepwise) by assimilatory DMS $S$-monooxygenase (EC 1.8.1.x) covered elsewhere in this chapter. SnfGF then catalyzes the oxidation of $\mathrm{DMSO}_{2}$ to methanesulfinate (MSiA):

$$
\left(\mathrm{CH}_{3}\right)_{2} \mathrm{SO}_{2}+\mathrm{FMNH}_{2}+\mathrm{O}_{2} \rightarrow\left(\mathrm{CH}_{3}\right) \mathrm{SO}_{2}{ }^{-}+\mathrm{HCHO}+\mathrm{H}_{2} \mathrm{O}
$$

The MSiA $\left(\left(\mathrm{CH}_{3}\right) \mathrm{SO}_{2}{ }^{-}\right)$is then chemically oxidized to methanesulfonate (MSA, $\left.\left(\mathrm{CH}_{3}\right) \mathrm{SO}_{3}{ }^{-}\right)$: 


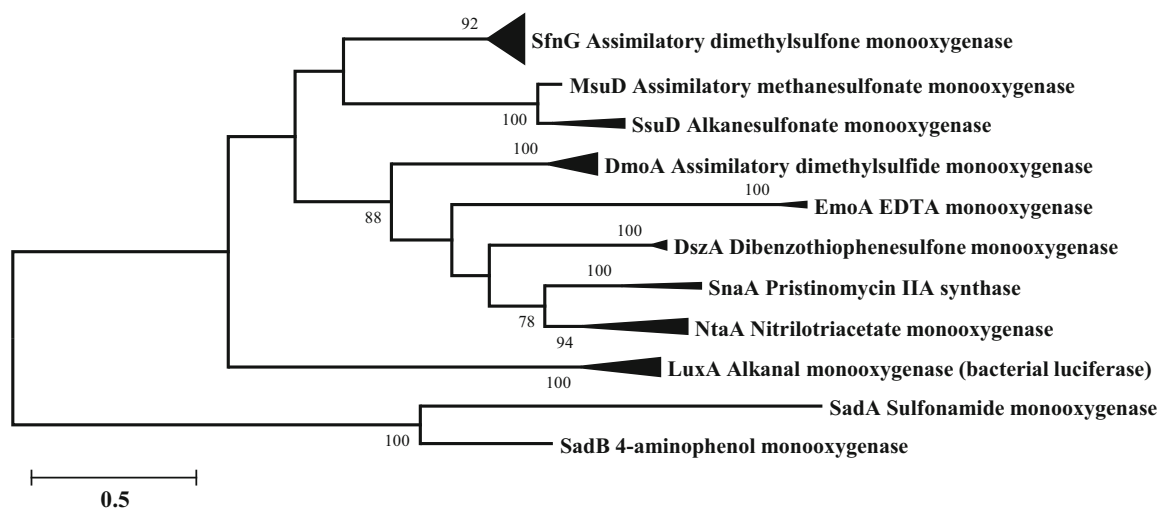

Fig. 2 Maximum likelihood tree constructed from amino acyl sequences from large subunits of FMN-dependent two-component monooxygenases, showing the distinction between the different monooxygenase groups - those involved in $\mathrm{C}_{1}$ organosulfur metabolism and otherwise. Amino acyl sequences were obtained from the GenBank and Integrated Microbial Genomes (IMG) databases and were aligned with MUSCLE (Edgar 2004) and model-tested in MEGA X (Kumar et al. 2018) to find the most suitable model on the basis of the lowest Bayesian information coefficient (BIC). Tree was built using the Le and Gascuel (2008) model with gamma distribution to model evolutionary rate differences (five categories, gamma parameter $=4.8871$ ). 5,000 bootstrap replications were undertaken, and numbers at nodes give the percentage of replicates in which these taxal clusters were found. Tree shown has the highest log likelihood (-14237.94) of all replications. Positions at which $<95 \%$ of sequences had a residue were discarded - final analysis used 310 residues. Sulfonamide degradation enzymes SadA and SadB were used as the outgroup

$$
\left(\mathrm{CH}_{3}\right) \mathrm{SO}_{2}{ }^{-} \rightarrow\left(\mathrm{CH}_{3}\right) \mathrm{SO}_{3}{ }^{-}
$$

The MSA is then further oxidized to formaldehyde and sulfite by MsuDE, the assimilatory methanesulfonate monooxygenase (EC 1.14.14.34), and the sulfite is assimilated into biomass as sulfur amino acids:

$$
\left(\mathrm{CH}_{3}\right) \mathrm{SO}_{3}{ }^{-}+\mathrm{O}_{2}+\mathrm{NADH}+\mathrm{H}^{+} \rightarrow \mathrm{HCHO}+\mathrm{SO}_{3}{ }^{2-}+\mathrm{NAD}^{+}+\mathrm{H}_{2} \mathrm{O}
$$

MsuDE is another two-component FMN-dependent monooxygenase and should not be confused with the dissimilatory methanesulfonate monooxygenase (EC 1.14.13.111) found in methylotrophic Bacteria such as Marinosulfonomonas methylotropha, Afipia felis, and Methylosulfonomonas methylovora (Baxter et al. 2002). The latter comprises the subunits MsmABCD and is a hybrid enzyme in many senses, with hydroxylase subunits MsmA and MsmB relating to Rieskecentered dioxygenases and electron transfer subunits MsmC and MsmD relating to monooxygenases (De Marco et al. 1999). Recently, msmA sequences were obtained from metagenomic and genomic libraries of marine and estuarine environments, including Filomicrobium and Candidatus Puniceispirillum marinum, further demonstrating the diversity of MSA utilizing methylotrophs (Henriques and De Marco 2015). MsmABCD oxidizes methanesulfonate to sulfite and formaldehyde by the same mechanism given above for MsuDE (Thompson et al. 1995; Kelly et al. 1994). 
Assimilatory $\mathrm{DMSO}_{2}$ monooxygenase and assimilatory MSA monooxygenase can be assayed per the method we give for dissimilatory DMS monooxygenase but using $\mathrm{DMSO}_{2}$ or MSA, respectively, in lieu of DMS. For dissimilatory MSA monooxygenase, the conventional assay has been to use 5,5'-dithiobis (2-nitrobenzoic acid), Ellman's reagent, to detect the sulfite produced; however, since this cross-reacts with cysteine, cystine, MT, sulfide, etc., we recommend that pararosaniline (Magenta ${ }^{\mathrm{TM}} \mathrm{O}$, Basic Red 9) and formaldehyde are used to determine sulfite, modifying the usual enzyme assay method of Higgins et al. (1996) accordingly - we use the method of Yoshiko et al. (1968) for sulfite - though of course ion chromatography or indeed formaldehyde assay could be used (cf. MT oxidase assay methods). It is worth noting that a rapid-screen version has also been published which may be useful in protein purification or in screening clones (Jamshad et al. 2007) or to check if the enzyme is being expressed in chemostat work when switching substrates.

\subsection{Putative Dissimilatory Dimethylsulfide Hydrolase}

In Boden et al. (2010), it was noted that aside from the dissimilatory DMS demethylase already discussed, a second oxygen-independent route to MT was possible in theory - though it may not be thermodynamically feasible, of course and would yield methanol rather than formaldehyde:

$$
\left(\mathrm{CH}_{3}\right)_{2} \mathrm{~S}+\mathrm{H}_{2} \mathrm{O} \rightarrow \mathrm{CH}_{3} \mathrm{SH}+\mathrm{CH}_{3} \mathrm{OH}
$$

Were this enzyme (a DMS hydrolase) present, the addition of a methanol dehydrogenase inhibitor such as cyclopropanol would lower the specific growth yield as assimilation would only be possible from the MT-carbon and not the methanolcarbon - as such, its existence in Methylophaga thiooxydans was ruled out, but it could be another route of dissimilation. No evidence exists for this "enzyme," but it remains a possibility.

\section{$5 \quad$ Ecological Theory and Strategies}

Ecological studies pertaining to the $\mathrm{C}_{1}$ organosulfur compounds thus far relate to isolation work and study of functional diversity using SIP, metagenomics, etc. An understanding of the ecological strategies and underpinning evolution is needed since some interesting questions now arise. Canonically, most organisms seem to "prefer" sulfite, sulfate, or thiosulfate as sulfur sources (Le Faou et al. 1990), whereas others "prefer" reduced sulfur such as methionine or dimethylsulfoniopropionate (DMSP) as their sulfur source (Tripp et al. 2008), and, indeed, seemingly cannot use sulfate, etc. Additionally, the assimilation of sulfur from, e.g., alkanesulfonates, taurine, MSA, DMS, etc. has been considered a "sulfur starvation" (Kertesz 1996; van der Ploeg et al. 1996) response, and (thio)sulfate and sulfite 
(hereafter "inorganics") are the "preferred" sulfur sources. In most common environments, inorganics will dominate - in the oceans, the standing concentration of sulfate is $c .30 \mathrm{mM}$ (Canfield and Farquhar 2009), whereas DMS is c. $2 \mathrm{nM}$ (Kloster et al. 2006) and DMSP is $c .5 \mathrm{nM}$ (Asher et al. 2017). If we make the assumption of totally equal mixing in a homogenous water column, an organism that can only use DMSP as a sulfur source would have to travel enormous distances versus one that uses inorganics in order to be able to assimilate sulfur. In this sense, the latter seems an unlikely strategy, since while it is using a resource with less competition, it is a scarce resource and is in an environment in which the more-competed-for resource is 600,000 times more abundant.

For the methylotroph growing on DMS and using sulfate as its sulfur source (e.g., H. sulfonivorans) versus the heterotroph growing on acetate but using DMS as its sulfur source (e.g., P. putida), some ecological and evolutionary considerations can be made. In an oxic, surface soil, the standing concentrations of DMS are up to $c$. $45 \mathrm{nmol} / \mathrm{kg}$ in soils (Lomans et al. 1997), sulfate $c .50 \mu \mathrm{mol} / \mathrm{kg}$ (Reussi Calvo et al. 2009), and acetate $c .1 \mathrm{mmol} / \mathrm{kg}$ (Sigren et al. 1997). Obviously this is a heterogeneous environment, but even so, the methylotroph is dealing with much lower concentrations of its $\mathrm{C}$ source versus the heterotroph - though it will be adapted for oligotrophic life (Hirsch 1986) - but the S source for the methylotroph is much more abundant than that of the heterotroph. As such, one would expect the heterotroph, if the canon of sulfate being the preferred source is correct (Le Faou et al. 1990), to use sulfate and to only consume DMS if the sulfate becomes limiting or if the cell enters a microenvironment low in sulfate. Of course, in nature, the methylotroph will be assimilating acetate and other multicarbon compounds, since it is of a facultative nature.

Should we then take the methylotroph from the last paragraph (which uses the De Bont pathway of DMS dissimilation) and the same environment also and add a second methylotroph that uses the Kino-Wicht pathway, oxidizing DMS ultimately to sulfite to assimilate the sulfur and assimilating the "waste" formaldehyde produced along the way - so acting much the same as the heterotroph from the last paragraph but using DMS for sulfur and carbon. In this circumstance, the second organism is using a low-abundance compound as a carbon and sulfur source and thus may have very limited growth - alternatively, it could be assimilating acetate per the heterotroph and only using the DMS for sulfur, but not wasting the formaldehyde as the heterotroph would - we could consider it as growing heterotrophically but with "methylotrophic mopping up" to avoid wasting $\mathrm{C}_{1}$ moieties formed during sulfur assimilation, perhaps, rather than necessarily growing methylotrophically.

It is hard to rationalize these various strategies in terms of traditional macroecological lifestyle models that have been applied to microbial systems, such as that of $r$ and $K$ selection (MacArthur and Wilson 1967; Pianka 1970) or, indeed, those that have not been applied to microbial systems, such as plant-focused Grime's triangle, or universal adaptive strategy theory (Grime 1979). The Silvertown-Franco demographic triangle (Silvertown et al. 1992) may provide a possible means in the future to compare effectively the properties of these organisms on the basis of their 
kinetic and biochemical parameters under ecophysiologically relevant conditions, such as cellular affinities for substrates (cf. Boden and Hutt 2018b).

\section{Research Needs}

The canon of work on $\mathrm{C}_{1}$ sulfur compound assimilation has grown enormously since the days of De Bont et al. (1981) and their seminal study, with the majority of the enzymes now known and purified or recombinantly expressed. There are, however, still holes in the story:

(a) The interplay of $\mathbf{C}$ and $\mathbf{S}$ assimilation. We need to understand the evolutionary and physiological (regulatory) rationale for the evolution of $\mathrm{C}_{1}$ organosulfur compound dissimilation for energy and for $\mathrm{C}$ assimilation versus oxidation in the "opposite direction" for S assimilation and any thermodynamic or kinetic influences or limitations that make this the case.

(b) Enzymology. The elusive dissimilatory DMS demethylase has still not been purified or identified after 25 years since Visscher and Taylor (1993a) first noted it, and a second "double demethylase" as observed by Padden (1997) could also exist, or a single demethylase could be acting twice. This enzyme needs identification, purification, and characterization. It is possible that the methanethiol $S$-methyltransferase (EC 2.1.1.334) could act in reverse to catalyze a similar reaction, but it lacks the properties of the enzyme observed by Visscher and Taylor (1993a) and Boden et al. (2010).

(c) Sulfur oxidation and energy metabolism. We already know that in some organisms such as Methylophaga spp., Thiobacillus spp., and Hyphomicrobium spp., the downstream oxidation of sulfide provides reducing equivalents $([\mathrm{H}])$ and thus proton-motive force $(\Delta p)$, which is consumed by ATP synthesis or, in Thiobacillus spp., in $\mathrm{NAD}(\mathrm{P}) \mathrm{H}$ generation by reverse electron transport. We need to understand the mechanisms and diversity of these oxidations and the full range of end products - sulfate, thiosulfate, and tetrathionate have been identified thus far - that organisms growing on these compounds produce and why.

(d) Ecology and strategism. Through ecophysiological work, modeling and chemostat competition studies, etc., we need to understand the whys and wherefores of the different $\mathrm{S}$ and $\mathrm{C}$ uptake pathways, their benefits and ecological relevance, and their evolution.

Acknowledgments We thank the EThOS service at the British Library for the rapid digitization of the Padden thesis used in this work. We thank Dr. Ann P Wood (previously of King's College London, UK) for discussions and being a sounding board and Dr. Miguel Franco (School of Biological and Marine Sciences, University of Plymouth) for discussions on evolutionary models. 


\section{References}

Ahlgren G (1925) Kapitel I: Methodik. Skand Arch Physiol 47(Suppl):6-17

Anness B (1981) The determination of dimethyl sulphoxide in aqueous solution. J Sci Food Agric 32:353-358

Aronoff S (1956) Techniques of radiobiochemistry. Iola State College Press, Ames

Asher E, Dacey JW, Ianson D, Peña A, Tortell PD (2017) Concentrations and cycling of DMS, DMSP, and DMSO in coastal and offshore waters of the Subarctic Pacific during summer, 2010-2011. J Geophys Res Oceans 122:3269-3286

Baxter NJ, Scanlan J, De Marco P, Wood AP, Murrell JC (2002) Duplicate copies of genes encoding methanesulfonate monooxygenase in Marinosulfonomonas methylotropha strain TR3 and detection of methanesulfonate utilizers in the environment. Appl Environ Microbiol 68:289-296

Beerli R, Borschberg H-J (1991) Preparation of $\left[{ }^{13} \mathrm{C}_{2}\right]$-DMSO. J Label Compd Radiopharm 29:957-961

Bilous PT, Weiner JH (1985) Dimethyl sulfoxide reductase activity by anaerobically grown Escherichia coli HB101. J Bacteriol 162:1151-1155

Bilous PT, Cole ST, Anderson WF, Weiner JH (1988) Nucleotide sequence of the $d m s A B C$ operon encoding the anaerobic dimethylsulphoxide reductase of Escherichia coli. Mol Microbiol 2:785-795

Bock H, Rittmeyer R (1992) Radikalionen $89^{1,2}$ einelektronen-oxidationen von diaryldisulfiden mit $\mathrm{AlCl}_{3} / \mathrm{H}_{2} \mathrm{CCl}_{2}$. Phosphorus Sulfur Silicon Relat Elem 68:261-291

Boden R, Hutt LP (2018a) Chemolithoheterotrophy: means to higher growth yields from this widespread metabolic trait. In: Rojo F (ed) Aerobic utilization of hydrocarbons, oils and lipids. Handbook of hydrocarbon and lipid microbiology. Springer, Cham

Boden R, Hutt LP (2018b) Determination of kinetic parameters and metabolic modes using the chemostat. In: Steffan R (ed) Consequences of microbial interaction with hydrocarbons, oils and lipids: biodegradation and bioremediation. Handbook of hydrocarbon and lipid microbiology. Springer, Cham

Boden R, Kelly DP, Murrell JC, Schäfer H (2010) Oxidation of dimethylsulfide to tetrathionate by Methylophaga thiooxidans sp. nov.: a new link in the sulfur cycle. Environ Microbiol 12:2688-2699

Boden R, Murrell JC, Schäfer H (2011a) Dimethylsulfide is an energy source for the heterotrophic marine bacterium Sagittula stellata. FEMS Microbiol Lett 322:188-193

Boden R, Borodina E, Wood AP, Kelly DP, Murrell JC, Schäfer H (2011b) Purification and characterization of dimethylsulfide monooxygenase from Hyphomicrobium sulfonivorans. J Bacteriol 193:1250-1258

Boden R, Cleland D, Green PN, Katayama Y, Uchino Y, Murrell JC, Kelly DP (2012) Phylogenetic assessment of culture collection strains of Thiobacillus thioparus, and definitive 16S rRNA gene sequences for T. thioparus, T. denitrificans, and Halothiobacillus neapolitanus. Arch Microbiol 194:187-195

Bolton HC, Ray ID (1992) The admiral's storm glass: coffee-table renaissance of an old weather instrument. Weather 47:89-97

Borodina E (2002) Bacterial metabolism of dimethylsulfone. PhD thesis, King's College London, London

Borodina E, Kelly DP, Rainey FA, Ward-Rainey NL, Wood AP (2000) Dimethylsulfone as a growth substrate for novel methylotrophic species of Hyphomicrobium and Arthrobacter. Arch Microbiol 173:425-437

Borodina E, Kelly DP, Shumann P, Rainey FA, Ward-Rainey NL, Wood AP (2002) Enzymes of dimethylsulfone metabolism and the phylogenetic characterization of the facultative methylotrophs Arthrobacter sulfonivorans sp. nov., Arthrobacter methylotrophus sp. nov., and Hyphomicrobium sulfonivorans sp. nov. Arch Microbiol 177:173-183

Brot N, Weissbach H (1965) Enzymatic synthesis of methionine. J Biol Chem 240:3064-3070 
Canfield DE, Farquhar J (2009) Animal evolution, bioturbation, and the sulfate concentration of the oceans. Proc Natl Acad Sci 106:8123-8127

Carrión O, Curson ARJ, Kumaresan D, Fu Y, Lang AS, Mercadé E, Todd J (2015) A novel pathway producing dimethylsulfide in bacteria is widespread in soil environments. Nat Commun 6:6579

Charlson RJ, Lovelock JE, Andreae MO, Warren SG (1987) Oceanic phytoplankton, atmospheric sulphur, cloud albedo and climate. Nature 326:655-661

Cinti DL, Thal SE (1977) Determination of formaldehyde by the Hantzsch reaction: interference by naturally occurring compounds. Anal Biochem 83:91-98

Cline JD (1969) Spectrophotometric determination of hydrogen sulfide in natural waters. Limnol Oceanogr 14:454-458

Dahl JU, Urban A, Bolte A, Sriyabhaya P, Donahue JL, Nimtz M, Larson TJ, Leimkühler S (2011) The identification of a novel protein involved in molybdenum cofactor biosynthesis in Escherichia coli. J Biol Chem 286:35801-35812

De Bont JAM, van Dijken JP, Harder W (1981) Dimethyl sulphoxide and dimethyl sulphide as a carbon, sulphur and energy source for growth of Hyphomicrobium S. J Gen Microbiol 127:315-323

De Marco P, Morades-Ferreira P, Higgins TP, McDonald I, Kenna EM, Murrell JC (1999) Molecular analysis of a novel methanesulfonic acid monooxygenase from the methylotroph Methylosulfonomonas methylovora. J Bacteriol 181:2244-2251

De Zwart JMM (1997) Ecophysiology and modelling of DMS metabolism by Methylophaga sulfidovorans. PhD thesis, Technical University of Delft

De Zwart JMM, Nelisse P, Kuenen J (1996) Isolation and characterization of Methylophaga sulfidovorans sp. nov.: an obligately methylotrophic, aerobic dimethylsulfide oxidizing bacterium from a microbial mat. FEMS Microbiol Ecol 20:261-270

Denkmann K, Grein F, Zigann R, Sieman A, Bergmann J, van Helmont S, Nicolai A, Pereira IA, Dahl C (2012) Thiosulfate dehydrogenase: a widespread unusual acidophilic $c$-type cytochrome. Environ Microbiol 14:2673-2688

Edgar RC (2004) MUSCLE: multiple sequence alignment with high accuracy and high throughput. Nucleic Acids Res 19:1792-1797

Eisenberg G (1943) Colorimetric determination of hydrogen peroxide. Ind Eng Chem Anal Ed $15: 327-328$

Endoh T, Habe H, Yoshida T, Nojiri H, Omori T (2003a) A CysB-regulated and sigma53-dependent regulator, SfnR, is essential for dimethyl sulfone metabolism of Pseudomonas putida strain DS1. Microbiology 149:991-1000

Endoh T, Kasuga K, Horinouchi M, Yoshida Y, Habe H, Nojiri H, Omori T (2003b) Characterization and identification of genes essential for dimethyl sulfide utilization in Pseudomonas putida strain DS1. Appl Microbiol Biotechnol 62:83-91

Endoh T, Habe H, Nojiri H, Yamane H, Omori Y (2005) The sigma54-dependent transcriptional activator SnfR regulates the expression of the Pseudomonas putida $s f n F G$ operon responsible for dimethyl sulphone utilization. Mol Microbiol 55:897-911

Eyice Ö, Myronova N, Pol A, Carrión O, Todd JD, Smith TJ, Gurman SJ, Cuthbertson A, Mazard S, Mennink-Kersten MASH, Bugg TDH, Anderson KK, Johnston AWB, op den Camp HJM, Schäfer H (2018) Bacterial SBP56 identified as a Cu-dependent methanethiol oxidase widely distributed in the biosphere. ISME J 12:145-160

Feil VJ, Huwe JK, Dulik DM, Fenselaum C (1988) Synthesis of ${ }^{13} \mathrm{C}$ - and ${ }^{14} \mathrm{C}$-labelled methanesulfinic and methanesulfonic acids. J Label Compd Radiopharm 25:1021-1025

Field L (1977) Disulfides and polysulfides. In: Oae S (ed) Organic chemistry of sulfur. Plenum Press, New York

Galus Z (1985) Carbon, silicon, germanium, tin, and lead. In: Bard AJ, Parsons R, Jordan J (eds) Standard potentials in aqueous solutions. Marcel Dekker, New York, pp 189-236

Gould WD, Kanagawa TJ (1992) Purification and properties of methyl mercaptan oxidase from Thiobacillus thioparus Tk-m. J Gen Microbiol 138:217-221

Grime JP (1979) Plant strategies and vegetation process. Wiley, New York 
Grossart H-P, Frindte K, Dziallas C, Eckert W, Tang KW (2011) Microbial methane production in oxygenated water column of an oligotrophic lake. Proc Natl Acad Sci 108:19657-19661

Hanlon SP, Holt RA, Moore GR, McEwan AG (1994) Isolation and characterisation of a strain of Rhodobacter sulfidophilus: a bacterium which grows autotrophically on dimethylsulfide as electron donor. Microbiology 140:1953-1958

Hatton AD, Malin G, McEwan AG, Liss PG (1994) Determination of dimethyl sulfoxide in aqueous solution by an enzyme-linked method. Anal Chem 66:4093-4096

Henriques AC, De Marco P (2015) Methanesulfonate (MSA) catabolic genes from marine and estuarine bacteria. PLoS One 10:e0125735

Higgins TP, Davey M, Trickett J, Kelly DP, Murrell JC (1996) Metabolism of methanesulfonic acid involves a multicomponent monooxygenase enzyme. Microbiology 142:251-260

Hirsch P (1986) Microbial life at extremely low nutrient levels. Adv Space Res 6:287-298

Hogenkamp HPC (1968) Enzymatic reactions involving corrinoids. Annu Rev Biochem 37:225-248

Horinouchi M, Kasuga K, Nojiri H, Yamane H, Omori T (1997) Cloning and characterization of genes encoding an enzyme which oxidizes dimethyl sulfide in Acinetobacter sp. strain 20B. FEMS Microbiol Lett 155:99-105

Horinouchi M, Yoshida T, Nojiri H, Yamane H, Omori T (1999) Polypeptide requirement of multicomponent monooxygenase DsoABCDEF for dimethyl sulfide oxidizing activity. Biosci Biotechnol Biochem 63:1765-1771

Jagota NK, Nair JB, Kurtulik PT (1995) Ion chromatography of methanesulfonic acid in pharmaceuticals. J Pharm Biomed Anal 13:1291-1295

Jamshad M, Murrell JC, Fülöp V (2007) Purification and crystallization of the hydroxylase component of the methanesulfonate monooxygenase from Methylosulfonomonas methylovora strain M2. Protein Expr Purif 52:472-477

Kanagawa T, Kelly DP (1986) Breakdown of dimethyl sulfide by mixed cultures and by Thiobacillus thioparus. FEMS Microbiol Lett 34:13-19

Kanagawa T, Mikami E (1989) Removal of methanethiol, dimethyl sulphide, dimethyl disulphide, and hydrogen sulphide from contaminated air by Thiobacillus thioparus Tk-m. Appl Environ Microbiol 55:555-558

Kanagawa T, Dazai M, Fukuoka S (1982) Degradation of $O, O$-dimethyl phosphorodithioate by Thiobacillus thioparus TK-1 and Pseudomonas AK-2. Agric Biol Chem 46:2571-2578

Karl DM, Beversdorf L, Björkman KM, Church MJ, Martinez A, Delong EF (2008) Aerobic production of methane in the sea. Nat Geosci 1:473-478

Kaufmann CRE (2015) Alternative routes to methyl mercaptan from $\mathrm{C}_{1}$-compounds. Dr. rer. nat. dissertation, Technischen Universität München

Keine RP (1993) Microbial sources and sinks for methylated sulfur compounds in the marine environment. In: Murrell JC, Kelly DP (eds) Microbial growth on $\mathrm{C}_{1}$ compounds. Intercept Ltd, Andover, pp 15-34

Keine RP (1996) Microbiological controls on dimethylsulfide emissions from wetlands and the ocean. In: Murrell JC, Kelly DP (eds) Microbiology of atmospheric trace gases. NATO ASI series, vol 39. Springer, Berlin, pp 205-225

Kelly DP (1978) Bioenergetics of chemolithotrophic bacteria. In: Bull AT, Meadow PM (eds) Companion to microbiology, selected topics for further study. Longman, London, pp 363-386

Kelly DP (1996) A global perspective on sources and sinks of biogenic trace gases: an atmospheric system driven by microbiology. In: Murrell JC, Kelly DP (eds) Microbiology of atmospheric trace gases. NATO ASI series, vol 39. Springer, Berlin, pp 1-16

Kelly DP, Malin G, Wood AP (1993) Microbial transformations and biogeochemical cycling of one-carbon substrates containing sulphur, nitrogen or halogens. In: Murrell JC, Kelly DP (eds) Microbial growth on $\mathrm{C}_{1}$ compounds. Intercept Ltd, Andover, pp 47-63

Kelly DP, Baker SC, Trickett J, Davey M, Murrell JC (1994) Methanesulphonate utilization by a novel methylotrophic bacterium involves an unusual monooxygenase. Microbiology $140: 1419-1426$ 
Kertesz MA (1996) Desulfonation of aliphatic sulfonates by Pseudomonas aeruginosa PAO. FEMS Microbiol Lett 137:221-225

Kim SJ, Shin HJ, Kim YC, Yang JW (2000) Isolation and purification of methyl mercaptan oxidase from Rhodococcus rhodochrous for mercaptan detection. Biotechnol Bioprocess Eng 5:465-468

Kino K, Murakami-Nitta T, Oishi M, Ishiguro S, Kirimura K (2004) Isolation of dimethyl sulfonedegrading microorganisms and application to odourless degradation of dimethyl sulfoxide. J Biosci Bioeng 97:82-84

Kloster S, Feichter J, Maier-Reimer E, Six KD, Stier P, Wetzel P (2006) DMS cycle in the marine ocean-atmosphere system - a global model study. Biogeosciences 3:29-51

Koch T, Dahl C (2018) A novel bacterial sulfur oxidation pathway provides a new link between the cycles of organic and inorganic sulfur compounds. ISME J. https://doi.org/10.1038/s41396018-0209-7

Kolatis LN, Bruynseels FJ, van Grieken RE, Andreae M (1989) Determination of methanesulfonic acid and non-sea-salt sulfate in single marine aerosol particles. Environ Sci Technol 23:236-240

Koval' IV (1993) Thiols as synthons. Russ Chem Rev 62:769-786

Koval' IV (1994) The chemistry of disulfides. Russ Chem Rev 63:735-750

Kumar S, Stecher G, Li M, Tamura K (2018) MEGA X: molecular evolutionary genetics analysis across computing platforms. Mol Biol Evol 35:1547-1549

Lang RF, Brown CJ (1991) Determination of dimethyl sulfoxide and dimethyl sulfone in air. Anal Chem 64:186-189

Le SQ, Gascuel O (2008) An improved general amino acid replacement matrix. Mol Biol Evol 25:1307-1320

Le Faou A, Rajogopal BS, Daniels L, Fauque G (1990) Thiosulfate, polythionates and elemental sulfur assimilation and reduction in the bacterial world. FEMS Microbiol Rev 6:351-381

Lodge JP Jr (1988) Determination of mercaptan content of the atmosphere. In: Lodge JP Jr (ed) Methods of air sampling and analysis, 3rd edn. CRC Press LLC, Boca Raton

Lomans B, Smolders A, Intven LM, Pol A, Op D, van der Drift C (1997) Formation of dimethyl sulfide and methanethiol in anoxic freshwater sediments. Appl Environ Microbiol 63:4741-4747

MacArthur R, Wilson EO (1967) The theory of island biogeography. Princeton University Press, Princeton

Marazano C, Maziere M, Berger G, Comar D (1977) Synthesis of methyl iodide- ${ }^{11} \mathrm{C}$ and formaldehyde- ${ }^{11} \mathrm{C}$. Int J Appl Radiat Isot 28:49-52

McAllan DT, Cullum TV, Dean RA, Fidler FA (1951) The preparation and properties of sulfur compounds related to petroleum. I. The dialkyl sulphides and disulfides. J Am Chem Soc 73:3627-3632

McDevitt CA, Hugenholtz P, Hanson GR, McEwan AG (2002a) Molecular analysis of dimethyl sulphide dehydrogenase from Rhodovulum sulfidophilum: its place in the dimethyl sulphoxide reductase family of microbial molybdopterin-containing enzymes. Mol Microbiol 44:1575-1587

McDevitt CA, Hanson GR, Noble CJ, Cheesman MR, McEwan AG (2002b) Characterization of the redox centers in dimethyl sulfide dehydrogenase from Rhodovulum sulfidophilum. Biochemistry 41:15233-15244

Meites L, Meites T (1948) Removal of oxygen from gas streams. Anal Chem 20:984-985

Menger FM, Elrington AR (1990) Rapid deactivation of mustard via microemulsion technology. J Am Chem Soc 112:8201-8203

Moses AJ (1964) Nuclear techniques in analytical chemistry. Pergamon, London

Murakami-Nitta T, Kurimura H, Kirimura K, Kino K, Usami S (2002) Continuous degradation of dimethyl sulfoxide to sulfate ion by Hyphomicrobium denitrificans WU-K217. J Biosci Bioeng 94:52-56

Nash T (1953) The colorimetric estimation of formaldehyde by means of the Hantzsch reaction. Biochem J 55:416-421 
Neufeld JD, Boden R, Moussard H, Schäfer H, Murrell JC (2008) Substrate-specific clades of active marine methylotrophs associated with a phytoplankton bloom in a temperate coastal environment. Appl Environ Microbiol 74:7321-7328

O’Donnell BV, Tew DG, Jones OT, England PJ (1993) Studies on the inhibitory mechanism of iodonium compounds with special reference to neutrophil NADPH oxidase. Biochem J 290:41-49

Ogata M, Fujii T, Yoshida Y (1979) Quantitative determination of urinary dimethyl sulfoxide and dimethyl sulfone by the gas chromatography equipped with a flame photometric detector. Ind Health 17:73-78

Padden AN (1997) Microbial degradation of organic sulfur compounds. PhD thesis, King's College London, London

Padden AN, Rainey FA, Kelly DP, Wood AP (1997) Xanthobacter tagetidis sp. nov., an organism associated with Tagetes species and able to grow on substituted thiophenes. Int J Syst Bacteriol 47:394-491

Padden AN, Kelly DP, Wood AP (1998) Chemolithoautotrophy and mixotrophy in the thiophene-2carboxylic acid-utilizing Xanthobacter tagetidis. Arch Microbiol 169:249-256

Palumbo SA, Alford JA (1970) Inhibitory action of tetrathionate enrichment broth. Appl Environ Microbiol 20:970-976

Park S-W, Lee W (2015) Development of a validated determination of methylsulfonylmethane in dietary supplements by gas chromatography. KSBB J 30:141-147

Paskach TJ, Schrader GL, McCarley RE (2002) Synthesis of methanethiol from methanol over reduced molybdenum sulfide catalysts based on the $\mathrm{Mo}_{6} \mathrm{~S}_{8}$ cluster. J Catal 211:285-295

Pianka ER (1970) On $r$ and $K$ selection. Am Nat 104:592-597

Quesenberry MS, Lee YC (1996) A rapid formaldehyde assay using purpald reagent: application under periodation conditions. Anal Biochem 234:50-55

Reussi Calvo NI, Echeverrì HE, Sainz Rozas H (2009) Determination of sulfate concentration in soil: depth of sampling. Commun Soil Sci Plant Anal 40(9-10):1624

Roberts JS (2000) Thiols. In: Ley C (ed) Kirk-Othmer encyclopedia of chemical technology. Wiley, New York

Ross PN (1985) Oxygen. In: Bard AJ, Parsons R, Jordan J (eds) Standard potentials in aqueous solutions. Marcel Dekker, New York, pp 49-66

Šatínský D, Pospíšilová M, Sladovský R (2014) A new gas chromatography method for quality control of methylsulfonylmethane content in multicomponent dietary supplements. Food Anal Methods 7:1118-1122

Schäfer H (2007) Isolation of Methylophaga spp. from marine dimethylsulfide-degrading enrichment cultures and identification of polypeptides induced during growth on dimethylsulfide. Appl Environ Microbiol 73:2580-2591

Schäfer H, Myronova N, Boden R (2010) Microbial degradation of dimethylsulphide and related $\mathrm{C}_{1}$-sulphur compounds: organisms and pathways controlling fluxes of sulphur in the biosphere. J Exp Bot 61:315-334

Sigren LK, Byrd GT, Fisher FM, Sass RL (1997) Comparison of soil acetate concentrations and methane production, transport, and emission in two rice cultivars. Global Biogeochem Cycles $11: 1-14$

Silvertown J, Franco M, McConway K (1992) A demographic interpretation of Grime's triangle. Funct Ecol 62:130-136

Smith NA (1988) Metabolism of dimethyl disulphide, carbon disulphide and other volatile sulphur compounds by chemolithoautotrophic sulphur bacteria. PhD thesis, University of Warwick

Smith NA, Kelly DP (1988) Mechanism of oxidation of dimethyl disulphide by Thiobacillus thioparus E6. J Gen Microbiol 134:3031-3039

Smith TJ, Murrell JC (2011) Mutagenesis of soluble methane monooxygenase. Methods Enzymol 495:135-147

Suylen GMH (1988) Microbial metabolism of dimethyl sulphide and related compounds. $\mathrm{PhD}$ thesis, University of Technology Delft 
Suylen GMH, Large PJ, van Dijken JP, Kuenen JG (1987) Methyl mercaptan oxidase, a key enzyme in the metabolism of methylated sulphur compounds by Hyphomicrobium EG. J Gen Microbiol 133:2989-2997

Suylen GMH, Stefess GC, Kuenen JG (1996) Chemolithotrophic potential of a Hyphomicrobium species, capable of growth on methylated sulphur compounds. Arch Microbiol 146:192-198

Suzuki I, Silver M (1966) The initial product and properties of the sulfur-oxidizing enzyme of thiobacilli. Biochim Biophys Acta 122:22-33

Takeuchi A, Yamamoto S, Narai R, Nishida M, Yashiki M, Sakui N, Namera N (2009) Determination of dimethyl sulfoxide and dimethyl sulfone in urine by gas chromatography-mass spectrometry after preparation using 2,2-dimethoxypropane. Biomed Chromatogr 24:465-471

Thompson AS, Owens NJP, Murrell JC (1995) Isolation and characterization of methanesulfonic acid-degrading bacteria from the marine environment. Appl Environ Microbiol 61:2388-2393

Tripp HJ, Kitner JB, Schwalbach MS, Dacey JW, Wilhelm LJ, Giovannoni SJ (2008) SAR11 marine bacteria require exogenous reduced sulphur for growth. Nature 452:741-744

van der Ploeg JE, Weiss MA, Saller E, Nashimoto H, Saito N, Kertesz MA, Leisinger T (1996) Identification of sulfate starvation-regulated genes in Escherichia coli: a gene cluster involved in the utilization of taurine as a sulfur source. J Bacteriol 178:5438-5446

Visscher PT, Taylor BF (1993a) A new mechanism for the aerobic catabolism of dimethyl sulfide. Appl Environ Microbiol 59:3784-3789

Visscher PT, Taylor BF (1993b) Aerobic and anaerobic degradation of a range of alkyl sulfides by a denitrifying marine bacterium. Appl Environ Microbiol 59:4083-4089

Visscher PT, Quist P, van Gemerden H (1991) Methylated sulfur compounds in microbial mats: in situ concentrations and metabolism by a colorless sulfur bacterium. Appl Environ Microbiol $57: 1758-1763$

Warner DR, Hoffman JL (1996) Suicide inactivation of thioether $S$-methyltransferase by ethyl vinyl sulfide. Biochemistry 35:4480-4484

Wicht DK (2016) The reduced flavin-dependent monooxygenase SfnG converts dimethylsulfone to methanesulfinate. Arch Biochem Biophys 604:159-166

Williams KIH, Whittemore KS, Mellin TN, Layne DS (1965) Oxidation of dimethyl sulfoxide to dimethyl sulfone in the rabbit. Science 149:203-204

Wood AP (1996) Sulfur, carbon and nitrogen interactions. In: Murrell JC, Kelly DP (eds) Microbiology of atmospheric trace gases. NATO ASI series, vol 39. Springer, Berlin, pp 281-295

Yao M, Henny C, Maresca JA (2016) Freshwater bacteria release methane as a by-product of phosphorus acquisition. Appl Environ Microbiol 82:6994-7003

Yoshiko A, Takejiro O, Iwaji I (1968) An improved photometric method for the determination of sulfite with pararosaniline and formaldehyde. Bull Chem Soc Jpn 41:1454-1456

Zhang L, Nelson KJ, Rajagopalan KV, George GN (2008) Structure of the molybdenum site of Escherichia coli trimethylamine $N$-oxide reductase. Inorg Chem 47:1074-1078

Zhdanov SI (1985) Sulfur, selenium, tellurium and polonium. In: Bard AJ, Parsons R, Jordan J (eds) Standard potentials in aqueous solutions. Marcel Dekker, New York, pp 93-126

Zhou B, Wang J, Guo Z, Tan H, Zhu X (2006) A simple colorimetric method for determination of hydrogen peroxide in plant tissues. Plant Growth Regul 49:113-118

Zinder SH, Brock TD (1978) Production of methane and carbon dioxide from methane thiol and dimethyl sulphide by aerobic lake sediments. Nature 273:226-228 